\title{
Numerical evaluation of temperature fields and residual stresses in butt weld joints and comparison with experimental measurements
}

\author{
Raffaele Sepe ${ }^{1}$, Alessandro De Luca ${ }^{2}$, Alessandro Greco $^{2}$, and Enrico Armentani ${ }^{3}$ \\ ${ }^{1}$ University of Salerno Department of Industrial Engineering \\ ${ }^{2}$ University of Campania Luigi Vanvitelli Department of Engineering \\ ${ }^{3}$ University of Naples Federico II Department of Chemical Engineering Materials and \\ Industrial Production
}

July 30, 2020

\begin{abstract}
This paper presents a novel numerical model, based on the Finite Element (FE) method, for the simulation of a welding process aimed to make a two-passes V-groove butt joint. Specifically, a particular attention has been paid on the prediction of the residual stresses and distortions caused by the welding process. At this purpose, an elasto-plastic temperature dependent material model and the "element birth and death" technique, for the simulation of the weld filler supply over the time, have been considered within this paper. The main advancement with respect to the State of the Art herein proposed concerns the development of a modelling technique able to simulate the plates interaction during the welding operation when an only plate is modelled, taking advantage of the symmetry of the joint; this phenomenon is usually neglected in such type of prediction models because of their complexity. Problems arising in the development of this modelling technique have been widely described and solved herein: transient thermal field generated by the welding process introduces several deformations inside the plates, leading to their interaction, never faced in literature. Moreover, the heat amount is supplied to the finite elements as volumetric generation of the internal energy, allowing overcoming the time-consuming calibration phase needed to use the Goldak's model, commonly adopted in literature. The proposed FE modelling technique has been established against an experimental test, with regard to the temperatures field and to the joint distortion. Predicted results showed a good agreement with experimental ones. Finally, the residual stresses distribution in the joint has been evaluated.
\end{abstract}

Numerical evaluation of temperature fields and residual stresses in butt weld joints and comparison with experimental measurements

Raffaele Sepe ${ }^{1, *}$, Alessandro De Luca ${ }^{2}$, Alessandro Greco $^{2}$, Enrico Armentani $^{3}$

1) Dept. of Industrial Engineering, University of Salerno, Via Giovanni Paolo II, 132 - 84084 - Fisciano (SA) - Italy

2) Dept. of Engineering, University of Campania "Luigi Vanvitelli" Via Roma, 29 - 81031 Aversa (CE), Italy

3) Dept. of Chemical, Materials and Production Engineering, University of Naples "Federico II" P.le V. Tecchio, 80 - 80125 Naples, Italy

Corresponding author: Raffaele Sepe, e-mailrsepe@unisa.it

Abstract

This paper presents a novel numerical model, based on the Finite Element (FE) method, for the simulation of a welding process aimed to make a two-passes V-groove butt joint. Specifically, a particular attention 
has been paid on the prediction of the residual stresses and distortions caused by the welding process. At this purpose, an elasto-plastic temperature dependent material model and the "element birth and death" technique, for the simulation of the weld filler supply over the time, have been considered within this paper.

The main advancement with respect to the State of the Art herein proposed concerns the development of a modelling technique able to simulate the plates interaction during the welding operation when an only plate is modelled, taking advantage of the symmetry of the joint; this phenomenon is usually neglected in such type of prediction models because of their complexity.

Problems arising in the development of this modelling technique have been widely described and solved herein: transient thermal field generated by the welding process introduces several deformations inside the plates, leading to their interaction, never faced in literature. Moreover, the heat amount is supplied to the finite elements as volumetric generation of the internal energy, allowing overcoming the time-consuming calibration phase needed to use the Goldak's model, commonly adopted in literature.

The proposed FE modelling technique has been established against an experimental test, with regard to the temperatures field and to the joint distortion. Predicted results showed a good agreement with experimental ones. Finally, the residual stresses distribution in the joint has been evaluated.

Keywords: Residual stress, Welding, FEM, Butt weld joint, Element "birth and death" technique.

Nomenclature

$h_{c}$ temperature dependent convective film coefficient

$k$ thermal conductivity

$m_{\text {seam }}$ mass of half welding bead

$n_{\text {component }}$ number of components of whole half welding bead

$q_{\text {latent }}$ latent heat per mass unit

$\dot{q}_{n}$ heat flux

$t_{\text {weld }}$ time necessary to travel a distance equals to the length of the single component

$\dot{u}^{\prime \prime \prime}$ volumetric generation of the internal energy

$v$ the welding speed

vol component $_{\text {volume of the single component }}$

vol $_{\text {seam }}$ volume of half welding bead

$C$ specific heat

$\mathrm{C}_{\text {eq }}$ equivalent carbon content

$\left[C^{\text {th }}\right]$ thermal stiffness

$\left[D^{e p}\right]$ total stiffness matrix

$\left[D^{e}\right]$ elastic stiffness matrix

$\left[D^{p}\right]$ plastic stiffness matrix

$E$ Young Modulus

$G$ Tangential modulus

$H$ temperature dependent film coefficient

$I$ welding current 
$L_{\text {component }}$ length of the single component

$L_{\text {seam }}$ length of welding bead

$Q$ heat input

$Q_{\text {component }}$ energy to be applied to the single components

$Q_{\text {latent }}$ latent heat

$Q_{\text {real }}$ energy supplied to the entire half welding seam

$Q_{\text {sensible }}$ sensible heat

$T_{a z}$ absolute zero of the thermal scale used for this work (Celsius degrees)

$T_{r}$ temperature of the environment transferring by radiation

$T_{s}$ solidus temperature

$T(x, y, z, t)$ temperatures distribution of the welded plate

$T_{0}$ initial temperature

$T_{[?]}$ temperature of the environment transferring heat by convection

$V$ voltage

$\epsilon$ surface emissivity

$\eta$ arc efficiency

$\nu$ Poisson ratio

$\rho$ density

$\sigma$ Stefan-Boltzmann constant

$\sigma_{\rho}$ tensile strength

$\sigma_{\varsigma}$ yield stress

DBEM Dual Boundary Elements Method

CMM Coordinate Measuring Machine

FEM Finite Element Method

FZ Fusion Zone

GMAW Gas Metal Arc Welding

HAZ Heat Affected Zone

MIG Metal Inert Gas

SMAW Shielded Metal Arc Welding

Introduction

Welding is among the most relevant joining techniques used in the structural field and it is particularly attractive for the transport field such as aerospace, automotive and rail, thanks to the advantages it offers in terms of weight saving, monolithic structures, design flexibility and costs. Notwithstanding such benefits, several issues could arise and compromise the efficiency and the performance of the structure. Specifically, defects, residual stresses, porosities, cracks propagation facilitation, distortions and the consequent misalignments of the joint can affect the monoliths due to the thermal cycles involved during the process, as widely 
described in several books by some authors such as Gunnort ${ }^{1}$ or Connor $^{2}$. The highly localized transient heat and the strongly non-linear temperature fields, characterizing the thermal cycles, combined with the subsequent non-uniform cooling phase, cause plastic deformations in both the Fusion Zone (FZ) and the Heat Affected Zone (HAZ), as a result of the non-uniform thermal expansion and contraction of the metal. ${ }^{3}$ Hence, at the end of the welding process, the structure will be characterized by residual stresses that, combined with the in-service loading conditions, could reduce the structural performance, cause assembly issues, and influence the fatigue and buckling strength. ${ }^{4-6}$ Therefore, the measurement of the residual stress-strain state of welded components supports the designers in the development of more efficient structures.

In fact, as many researchers investigated on these issues, there is an extensive literature concerning the evaluation techniques of the residual stresses in welded joints. Wide literature reviews have been proposed by Makerle ${ }^{7}$ and by Dong ${ }^{8}$.

Over the last years, several destructive and non-destructive techniques have been developed to experimentally evaluate the residual stresses. ${ }^{9-16}$ Among these techniques, the most used ones are the non-destructive ultrasonic techniques, used for example by Satymbau and Ramachandrani ${ }^{9}$, the non-destructive neutron ${ }^{12,13}$ and X-ray ${ }^{14}$ diffraction techniques and the destructive hole drilling technique, used by Schajer ${ }^{16}$. However, these techniques show several limits such as the inaccuracies affecting the measures and the high costs. Current computational methods allow overcoming these limitations by simulating the welding processes and determining the stress-strain state; among these, Finite Element (FE) method appears to be the most suitable.

During the last decades, several scientific articles proposed FE models able to simulate complex welding processes. Typically, due to the coexistence of thermal and mechanical phenomena, the development of numerical models for welding structures can be very challenging; so, several strategies could be applied.

A comparison between the modelling strategies based on $\mathrm{FE}$ method has been proposed by Mollicone et al ${ }^{17}$ in 2006, while Lindgren, in 2001, presented a detailed review about the state of art related to the FE modelling and to the simulation of the welding processes in three articles. ${ }^{18-20}$ Among the many developed techniques, the so-called "element birth and death" is one of the most used. Briefly, it starts by the modelling of the entire weld seam. Subsequently, the finite elements of the seam are deactivated and progressively reactivated only when the heat is supplied, as explained in detail in section 2 . The literature presents various researches based on the use of such simulation technique, for different welding processes.

Teng and Chang ${ }^{18,19}$ used the element birth and death technique for simulating the welding process for butt joints made of carbon steel. They used the X-ray diffraction technique for validating the numerical results. Based on the same technique, Armentani et $\mathrm{al}^{23-25}$, in three consecutive studies between 2006 and 2007, simulated the welding processes for butt welded joints by varying such properties as the weld filler and the thermal material properties. In 2014, the same FE model was established against some experiments. ${ }^{26}$ Kermanpur et $\mathrm{al}^{27}$ investigated on butt welded joints, for pipe applications, by using the element birth and death approach. They validated the numerical model against some experimental tests and performed a further sensitivity analysis by changing the arc efficiency and the heat source values in input. Subsequently, Sepe et $\mathrm{al}^{28,29}$ used the same technique for simulating the welding processes of two butt welded joints, made of similar and dissimilar materials, respectively.

More recently, Modal et $\mathrm{al}^{30}$ in 2017 investigated on the residual stresses in a multi-pass welded T-joint by using a FE model, based on the element birth and death technique, validated by comparing numerical and experimental results. Hashemzadeh et $\mathrm{al}^{31}$ focused their investigation on butt welded joints. Finally, Tsirkas ${ }^{32}$, in 2018, proposed and validated an element birth and death technique-based model for simulating a laser welding process for aircraft components made of aluminium.

Other modelling and simulation techniques have been developed and applied for welding processes. Choi and Mazumder ${ }^{33}$ proposed a 3D transient FE model for simulating a Gas Metal Arc Welding (GMAW) process. Tsirkas et $\mathrm{al}^{34}$, in 2003, proposed a 3D FE model for simulating a laser welding process, considering also the metallurgical transformations, by using a nonlinear heat transfer analysis, based on a keyhole formation 
model, and a coupled transient thermo-mechanical analysis. Similarly, Cho et al ${ }^{35}$ investigated on the residual stresses in a butt-welded joint and validated the FE model by means of experimental tests based on the hole drilling technique. Gary et $\mathrm{al}^{36}$ carried out a thermal FE simulation of a butt joint developed by a Metal Inert Gas (MIG) welding process and studied the influence of the welding parameters on the temperature fields. Citarella et al ${ }^{37,38}$ developed a Dual Boundary Elements Method (DBEM) based model and a coupled FEM/DBEM for investigating the influence of the residual stresses on the cracks propagation in friction stir welded aluminium butt joint. Other simulation techniques are based on analytical models, as proposed by Mochizuki et $\mathrm{al}^{39}$, that evaluate the residual stresses in a pipe butt welded joint and validate the model by means of a neutron diffraction experimental test. Similarly, another analytical model for friction stir welding has been proposed by Vilaça et $\mathrm{al}^{40}$, while Binda et $\mathrm{al}^{41}$ proposed a semi-empirical model, based on analytical solving approach, for simulating a laser welding process and evaluating the temperature fields.

Almost all of the aforementioned simulation models use the Goldak's model ${ }^{42,43}$ to solve the thermal and the mechanical equations, considering either the double-ellipsoid heat source model or the Gaussian heat source model. Nevertheless, Goldak's model requires an extremely accurate calibration phase before proceeding with the simulation of the entire process. This calibration is based on experimental measurements and requires several control cycles, representing a time consuming process. ${ }^{44}$

In this study a novel FE model, based on the "element birth and death" technique, has been developed by means of ABAQUS ${ }^{\circledR}$ v. 6.14 code for the simulation of a welding process that can be applied for several types of joints (e.g. butt joint, T-joint,...). Among the main proposed elements of novelty, the modelling of the heat input has to be mentioned. The heat amount is supplied to the finite elements as volumetric generation of the internal energy. Such technique does not require any calibration phase as for Goldak's model $^{17,27,32,33,34,44}$, so the modelling time is significantly reduced.

A two-passes $\mathrm{V}$-groove butt welded joint, involving two plates characterized by the same material and geometry, has been investigated herein. Taking advantage of the joint symmetry, the FE model has been developed by modelling an only plate and a half seam to reduce the computational costs. Concerning the mechanical analysis, a new modelling strategy is proposed. It consists in simulating the interaction between the two joint counterparts, never considered in the FE models presented in literature. ${ }^{17,21,22,31,34,36}$

In order to assess the reliability of the proposed numerical procedure, numerical results have been compared with those provided by an experimental test, herein presented. For such purpose, temperatures distribution has been measured during the welding process by using some thermocouples placed at different locations nearby the weld bead; welding distortions have been subsequently measured by means of a Coordinate Measuring Machine (CMM). A very good agreement has been achieved, demonstrating the efficiency of the proposed model.

\section{Materials and methods}

Two carbon steel plates of size $248 \mathrm{~mm}$ x $125 \mathrm{~mm}$ (thickness of $8 \mathrm{~mm}$ ) which form a single V-groove joint between them (Figure 1A) have been welded by using the Shielded Metal Arc Welding (SMAW) process. The material of the plates is a structural low carbon steel S275JR. The typical chemical composition of the material used in the experimental test and the mechanical properties at room temperature are reported in Tables 1 and 2, respectively. The welding process has been carried out through two passes and a time gap of 108 between the successive passes has been addressed to remove the slag formed during the first pass. The welding parameters, related to each pass, are reported in Table 3. Both weld passes have been carried out at uniform speed and under room conditions using a $2.5 \mathrm{~mm}$ diameter flux-coated SMAW electrode ESAB OK 48.50 (AWS E 7018). The weld bead sequence is shown in Figure 1B and the start point (A) and the end point (B) of each welding pass are shown in Figure 1C. The plates have been simply placed on the work table shown in Figure 1D. In this arrangement, the most parts of the top and bottom surface areas of the plates are exposed to the environmental conditions. 


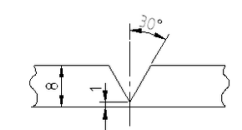

a)

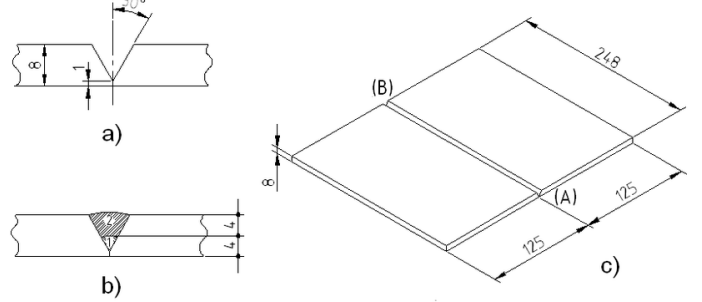

b)

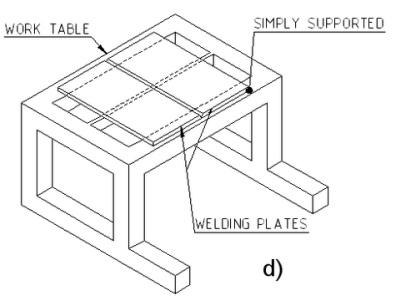

Figure 1 Dimensional details of plates and boundary conditions used during the welding process in the experimental test.

Table 1 Chemical composition (wt\%) of S275JR steel.

\begin{tabular}{lllll}
\hline $\mathrm{C}$ & $\mathrm{Mn}$ & $\mathrm{P}_{\max }$ & $\mathrm{S}_{\max }$ & $\mathrm{C}_{\text {eqmax }}$ \\
\hline $0.12 \div 0.18$ & $0.3 \div 0.6$ & 0.04 & 0.05 & 0.28 \\
\hline
\end{tabular}

Table 2 Mechanical properties of the base materials at room temperature.

\begin{tabular}{llllll}
\hline Material & $\sigma_{\mathrm{S}}[\mathrm{MPa}]$ & $\sigma_{\rho}[\mathrm{MPa}]$ & $E[\mathrm{GPa}]$ & $G[\mathrm{GPa}]$ & $\nu$ \\
\hline S275JR & 275 & 430 & 210 & 89.8 & 0.3 \\
\hline
\end{tabular}

In order to assess the reliability of the proposed FE model and, in particular, the validity of the thermal simulations results, six $K$-type thermocouples have been arranged at different distances (Figures $2 \mathrm{~A}$ and 2B) from the weld beads in order to monitor the temperatures distribution: two thermocouples, TC1 and $\mathrm{TC} 2$, at a quarter region of the plate and at the mid-plane level $(y=62 \mathrm{~mm}, z=4 \mathrm{~mm})$, the remaining, TC3, TC4, TC5 and TC6 have been fixed at the middle region of the plate and at the mid-plane level $(y$ $=124 \mathrm{~mm}, z=4 \mathrm{~mm})$. To record the values of temperatures, a personal computer with a PCI 6221 DAQ (Data AcQuisition) card of National Instrument and LabView ${ }^{\circledR} 2018$ software have been used. Moreover, during the welding process, both voltage and current have been measured using a voltmeter and an ammeter, respectively, both connected to the weld circuit. 

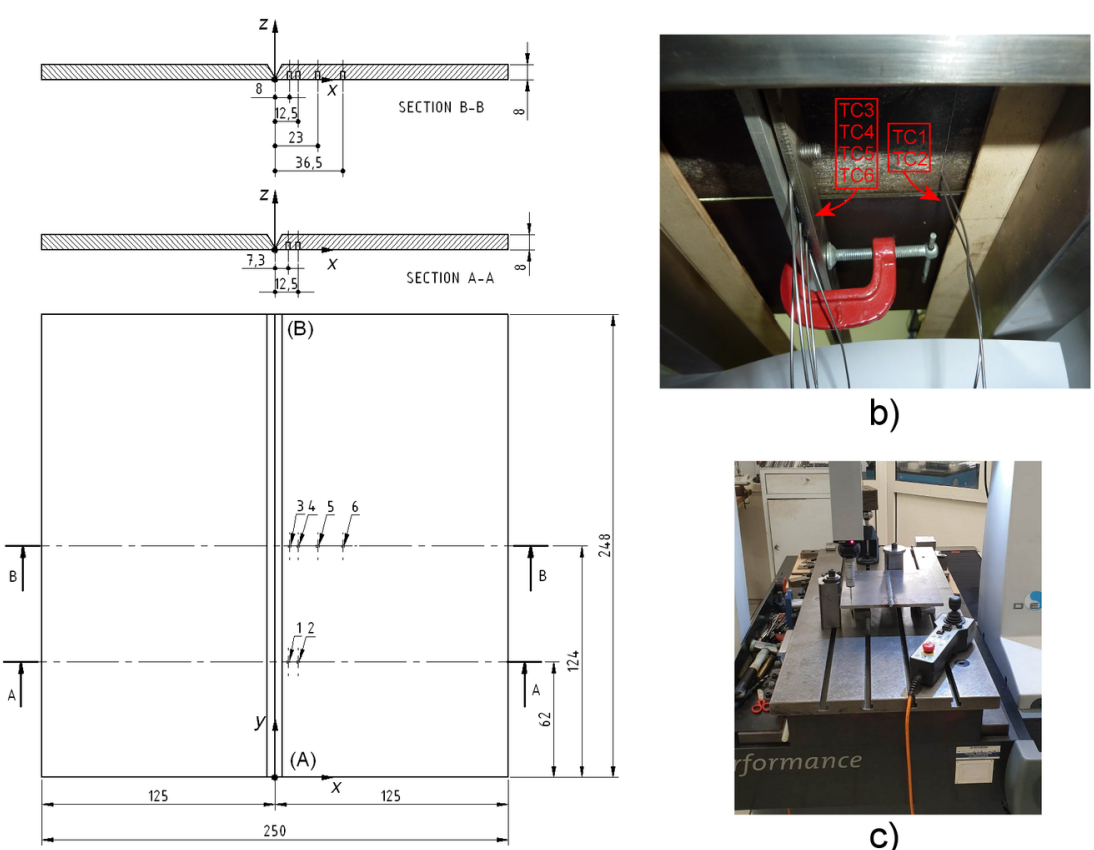

b)

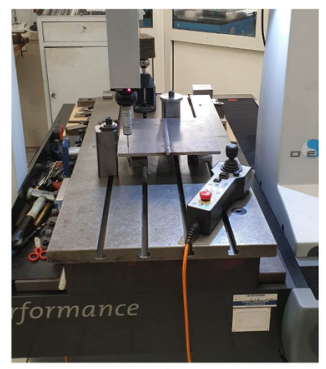

c)

a)

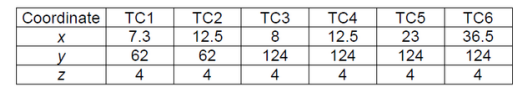

Figure 2 Layout of thermocouples A; thermocouples installed B; distortion of the welding joint measured by means CMM C.

An arc efficiency, $\eta$, of 0.82 for $\mathrm{SMAW}^{45}$ has been considered; therefore, the heat input per mm of weld length, $Q$, can be calculated using the equation (1);

$X=\eta^{\circ} \mathrm{T} /(1)$

where $\eta$ is arc efficiency; $V$, the voltage; $I$, the current and $v$, the welding speed. The values of $Q$ are also reported in Table 3.

Table 3 Welding parameters.

\begin{tabular}{|c|c|c|c|c|c|c|c|}
\hline Pass & Efficiency $\eta$ & $\begin{array}{l}\text { Wire } \\
\text { diameter } \\
{[\mathrm{mm}]}\end{array}$ & $\begin{array}{l}\text { Current } I \\
{[\mathrm{~A}]}\end{array}$ & $\begin{array}{l}\text { Voltage } V \\
{[\mathrm{~V}]}\end{array}$ & $\begin{array}{l}\text { Travel speed } \\
v[\mathrm{~mm} / \mathrm{s}]\end{array}$ & $Q[\mathrm{~J} / \mathrm{mm}]$ & $\begin{array}{c}\dot{u}^{\prime \prime \prime} \\
{\left[\mathrm{W} / \mathrm{mm}^{3}\right]}\end{array}$ \\
\hline 1 & 0.82 & 3.2 & 108 & 29.5 & 1.56 & 1674.7 & 62.372 \\
\hline 2 & & & 98 & 26.0 & 2.166 & 964.62 & 23.829 \\
\hline
\end{tabular}

In order to assess the reliability of the proposed FE model to evaluate the welding distortion, the $u_{z}$ (Figure $2 \mathrm{C}$ ) displacements of the plate have been measured at some locations of the joints, by means of a Coordinate Measuring Machine (CMM).

2. Finite element model

The numerical simulation of a welding process involves the investigation of the thermo-mechanical response of the joint. This behaviour can be simulated by a numerical method, by using an uncoupled approach consisting of two consecutive analyses: the former, where the thermal problem is solved independently on 
the joint mechanical response, under a free-free configuration, to obtain the temperatures distribution; the latter, consisting of a subsequent mechanical analysis, where the temperatures history previously predicted at each node is used as thermal load. Such uncoupled approach, which is well established in literature for such type of analyses, ${ }^{17,22,34}$ allows saving computational costs with respect to the coupled one, with a comparable and an acceptable level of accuracy. All simulations have been carried out by means of the finite element commercial code ABAQUS ${ }^{\circledR}$ v. 6.14.

The same FE model has been used for both thermal and mechanical analyses. Concerning the mesh, 8-nodes hexahedral 3D finite elements have been used for both base and weld zones. More in detail, DC3D8 finite elements have been used for the thermal analysis, allowing introducing the temperature as unique degree of freedom, and C3D8 finite elements, characterized by the three translations as degrees of freedom, has been used for the mechanical analysis. According to Figure 3, a finer mesh has been developed for the chamfer region; a transition mesh for the HAZ (Heat Affected Zone) region and a coarser mesh, with a linear bias, for the other parts of the plate. As a result, FE model counts a total of 11904 finite elements and 14175 nodes.

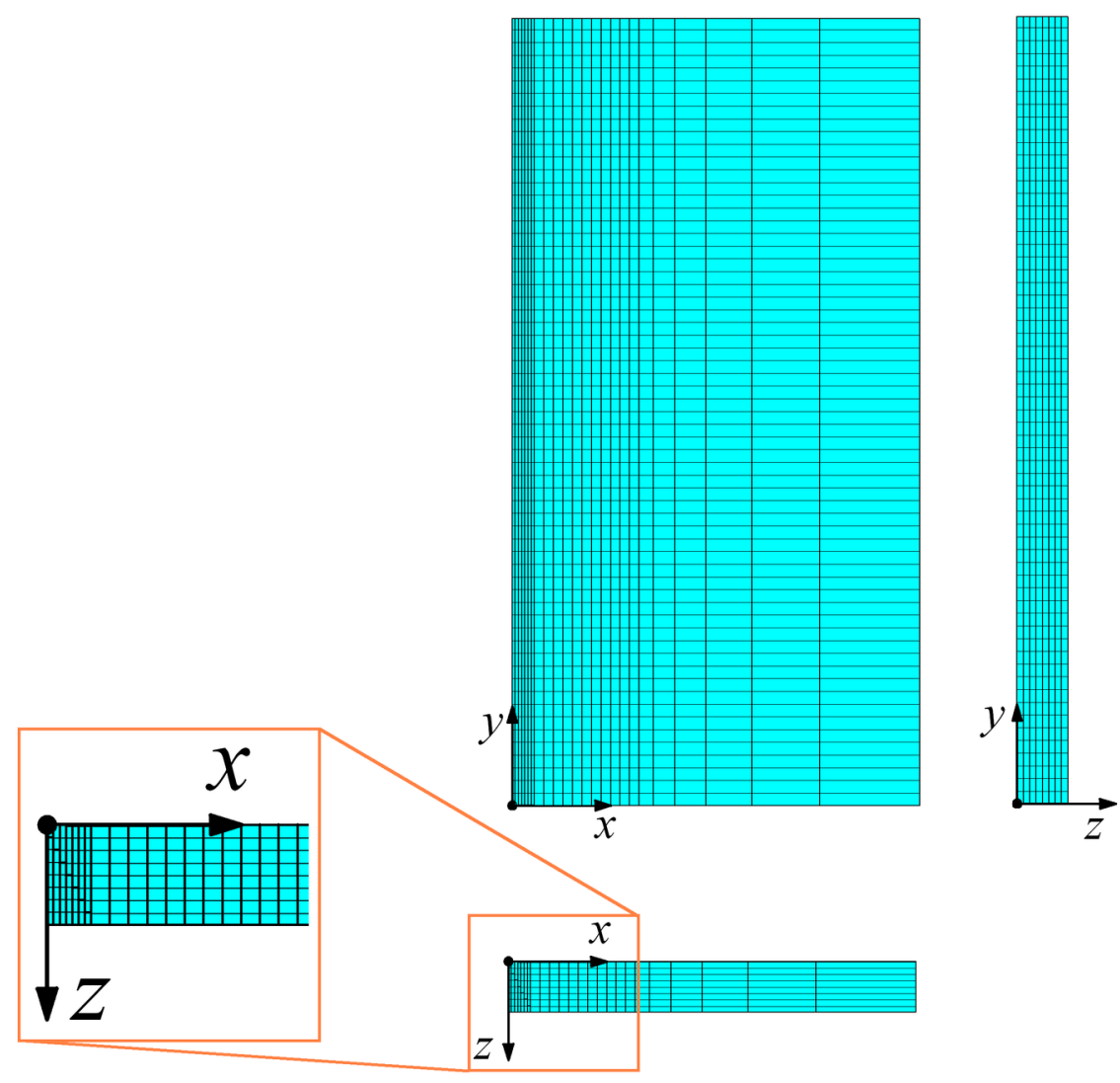

Figure 3 Finite element model.

Moreover, the simulation of the weld passes has been carried out according to the element birth and death technique. Such technique starts by the modelling of the whole weld bead (Figure 4A), by separating it in 124 groups of finite elements (64 for each weld pass), named in the following "components" (Figure 4B). Subsequently, all elements are deactivated by multiplying their properties by a severe reduction factor (e.g. $10^{-6}$ ) in a way to exclude them from the simulation. When the added material needs to be simulated in order to virtually perform the welding process, it is not actually added to the model, but it is progressively reactivated, component by component: material properties of the finite elements belonging to the weld seam 
return to their starting values, participating again to the evolution of the joint material.

The model has been developed by taking advantage of the symmetry of the joint geometry and of the use of the same material for all joint parts (weld bead included). Under this condition, it is possible to simulate the experimental test just by modelling one plate and a half seam.

Both thermal and mechanical analyses involve a first step, $1 \cdot 10^{-4} \mathrm{~s}$ long, during which all "components" simulating the whole weld seam are removed. Then, 62 couples of load steps, corresponding to about 158.97 $\mathrm{s}$, are alternatively set to simulate the first weld pass (Figure 4B - red elements). Each couple consists of a first step, $1 \cdot 10^{-4} \mathrm{~s}$ long, which allows reactivating a single "component"; a second step, which allows simulating the thermal load on the previously reactivated "component" (the duration time, in this case, depends on the weld speed). Before simulating the second pass, a load step, $108 \mathrm{~s}$ long, is set to simulate the time dedicated to the first weld seam cleaning operations. Afterwards, other two groups of 62 load steps, corresponding to about $114.5 \mathrm{~s}$ are set to simulate the second pass (Figure $4 \mathrm{~B}$ - blue elements) according to the same modelling technique of the first pass. Finally, a load step, $1886 \mathrm{~s}$ long, has been set to simulate the plate cooling phase up to a temperature of about $60{ }^{\circ} \mathrm{C}$. The $\mathrm{FE}$ analysis time increment is automatically calculated by the software and a full Newton-Raphson method is used to obtain the incremental calculation.

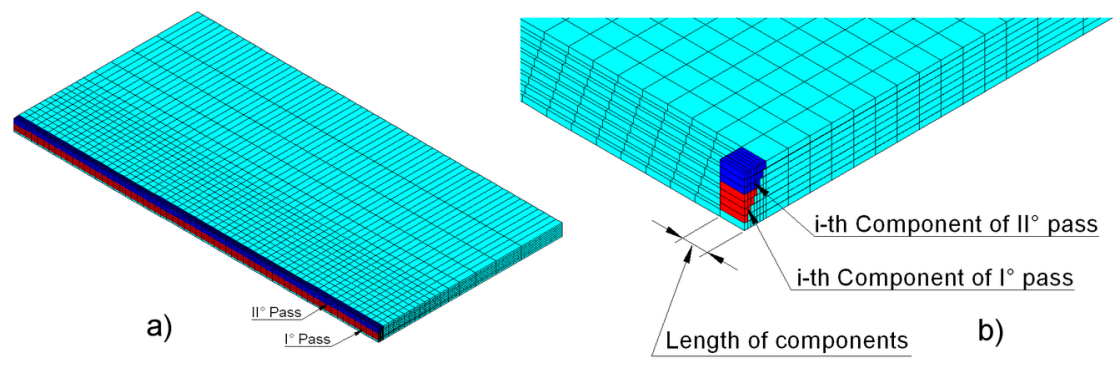

Figure 4 Representation of the "components" with indication of the two groups of elements constituting the two passes A; i-th red components of first pass, i-th blue components of second pass B.

Thermal analysis

The thermal analysis of the welding process is essentially a mathematical solution of the differential problem based on the equation of energy conservation:

$\rho^{\text {с }} \frac{\partial T}{\partial t}=\dot{u}^{\prime \prime \prime}+\frac{\partial}{\partial x}\left(k_{x} \frac{\partial T}{\partial x}\right)+\frac{\partial}{\partial y}\left(k_{y} \frac{\partial T}{\partial y}\right)+\frac{\partial}{\partial z}\left(k_{z} \frac{\partial T}{\partial z}\right)$,

where the temperatures distribution $T(x, y, z, t)$ of the welded plate is a function of both spatial and time coordinates; $\rho, C$ and $k$ are the density, the specific heat and the thermal conductivity of the material, respectively, and $\dot{u}^{\prime \prime \prime}$ is the change rate of internal energy per volume unit. Eq. (2) is a non-linear differential equation since $\rho, C$ and $k$ depend on the temperature. Initial and boundary conditions of the problem are respectively:

$T(x, y, z ; t=0)=T_{0},(3)$

$\dot{q}_{n}(x, y, z ; t)=-\left(k_{x} \frac{\partial T}{\partial x} n_{x}+k_{y} \frac{\partial T}{\partial y} n_{y}+k_{z} \frac{\partial T}{\partial z} n_{z}\right)$,

where $T_{0}=23.5^{\circ} \mathrm{C}$ is the initial temperature of the material; $\dot{q}_{n}$ is the heat flux at a generic boundary having an outward local unit vector $\hat{n}(x, y, z)$. In welding problems, at external surfaces, the heat flux $\dot{q}_{n}$ may consist of one or more of the following modes: convective heat loss, radiative heat loss and boundary heat $\dot{q}_{0}$. The latter has been neglected in the proposed FE model. Convective and radiative heat losses on the external surfaces of the welded plates are given respectively by:

$\dot{q}_{\mathrm{nc}}=h_{c}\left[T(x, y, z ; t)-T_{\infty}\right],(5)$ 
$\dot{q}_{\mathrm{nr}}=\varepsilon \sigma\left\{\left[T(x, y, z ; t)-T_{\mathrm{az}}\right]^{4}-\left(T_{r}-T_{\mathrm{az}}\right)^{4}\right\}=h_{r}\left[T(x, y, z ; t)-T_{r}\right]$,

where $T_{[?]}$ and $T_{r}$ are respectively the temperatures of the environment transferring heat by convection and radiation and they are usually equal to the room temperature; $\epsilon$ is the surface emissivity; $\sigma=5.67 \cdot 10^{-8}$ $\mathrm{W} / \mathrm{m}^{2} \mathrm{~K}^{4}$ is the Stefan-Boltzmann constant; $h_{c}$ is the temperature dependent convective film coefficient and $T_{a z}=-273.15{ }^{\circ} \mathrm{C}$ is the absolute zero of the thermal scale used for this work (Celsius degrees). From Eq. (6) the radiative heat losses can be expressed in the form of convective heat losses by means of temperature dependent convective film coefficient $h_{r}$, therefore from Eq. (5) and (6) a unique temperature dependent film coefficient, $H$, can be considered:

$H=h_{c}+h_{r} \cdot(7)$

Particularly important in the thermal model is the heat input per $\operatorname{mm} Q$, reported in Table 3 . This is the energy supplied by the welding machine per unit of length. In the proposed simulation a half of this energy has been supplied to a half of the seam because one plate only has been modelled. Therefore, energy supplied to the entire half welding seam during the simulation is equal to:

$Q_{\text {real }}=\frac{Q \bullet L_{\text {seam }}}{2},(8)$

where: $L_{\text {seam }}$ is the length of welding bead.

This energy can be subdivided into three parts:

sensible heat : energy to heat the weld material from the initial temperature $\left(T_{0}\right)$ to the solidus temperature $\left(T_{s}\right)$ :

$Q_{\text {sensible }}=\operatorname{vol}_{\text {seam }} \bullet \int_{T_{0}}^{T_{S}} \rho^{\text {" }} \delta \mathrm{T}=m_{\text {seam }} \int_{T_{0}}^{T_{S}} \mathrm{C} \mathrm{dT},(9)$ where: $\rho$ and $C$ are the density and specific heat of the material respectively and $v o l_{\text {seam }}$ and $m_{\text {seam }}$ are the volume and the mass of half welding bead;

latent heat : energy due to phase transition from the solidus temperature $\left(T_{S}\right)$ to the liquidus temperature $\left(T_{L}\right)$ :

$Q_{\text {latent }}=m_{\text {seam }} \bullet q_{\text {latent }},(10)$ where: $m_{\text {seam }}$ is the mass of half welding bead and $q_{\text {latent }}$ is the latent heat per mass unit;

the energy to further heat the weld material is equal to:

$Q_{\text {body flux }}=Q_{\text {real }}-Q_{\text {sensible }}-Q_{\text {latent }},(11)$ while the energy to be applied to the single components is: $Q_{\text {component }}=\frac{Q_{\text {body flux }}}{n_{\text {component }}},(12)$ where: $n_{\text {component }}$ is the number of components of whole half welding bead. This latter part of the energy acts as volumetric generation of the internal energy $\dot{u}^{\prime \prime \prime}$ (Table 3 ) and it is computable by Eq. $13: \dot{u}^{\prime \prime \prime}=\frac{Q_{\text {component }}}{\text { vol }_{\text {component }} \bullet t_{\text {weld }}}=\frac{Q_{\text {body flux }}}{n_{\text {component }}} \bullet \frac{v}{\text { vol }_{\text {component }} \bullet L_{\text {component }}}=\frac{Q_{\text {body flux }} \bullet v}{\text { vol } v \text { seam } \bullet L_{\text {component }}},(13)$ where: vol component and $L_{\text {component }}$ are the volume and the length of the single component, respectively; $v$ is the welding speed and $t_{\text {weld }}$ is the time necessary to travel a distance equals to the length of the single component by Eq. (14); $t_{\text {weld }}=\frac{L_{\text {component }}}{v}$. (14)

In the proposed FE model, the specific power $\dot{u}^{\prime \prime \prime}$ has been applied to each component during the timet $t_{w e l d}$ as volumetric flux and it has been applied by means of the law shown in Figure 5.

The load has been applied so that the area under the load curve is constant and equals to $\dot{u}^{\prime \prime \prime}$ at varying travel time $\left(t_{\text {weld }}\right)$. Two ramps [with duration of $0.5 \%$ of $t_{\text {weld }}$ ], to avoid the discontinuity during the load application, and a little time offset of $2 \cdot 10^{-6} s$ between two load curves have been defined, in order to encourage the convergence of the solution. The height of the trapezium $h$ is computable by Eq. (15):

$\dot{u}^{\prime \prime \prime}=A_{\text {trapezium }}=\frac{(B+b) \bullet h}{2}=\frac{\left\{\left(1 \bullet t_{\text {weld }}\right)+\left[(1-2 \bullet 0.005) t_{\text {weld }}\right]\right\} \bullet h}{2}=(1-0.005) \bullet t_{\text {weld }} \bullet h(15)$

and hence:

$h=\frac{\dot{u}^{\prime \prime \prime}}{(1-0.005) \bullet t_{\mathrm{weld}}}$. 


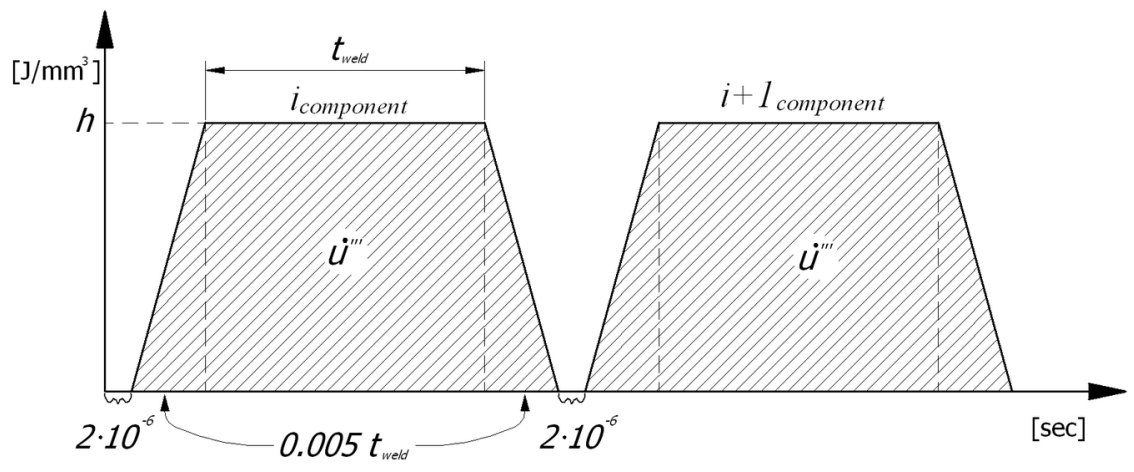

Figure 5 Load curve.

Thermal boundary conditions, given by Eqs. (3) and (4), occur at all the surfaces except the adiabatic plane at the longitudinal symmetry plane of the final joint; in the same manner, for numerical simplicity, the surfaces of the chamfer hollow have been considered adiabatic before supplying the filler material.

Thermal properties dependent on temperature ${ }^{46,47}$ are reported in Figure $6 \mathrm{~A}$. In order to take into account the transformation phase in the thermal analysis, a latent heat per mass unit, a solidus temperature and a liquidus temperature equals to $277000 \mathrm{~J} / \mathrm{kg}, 1495{ }^{\circ} \mathrm{C}, 1540{ }^{\circ} \mathrm{C}$ respectively, have been used, whereas the temperature dependent heat loss coefficient $H$, applied on the surfaces, is shown in Figure 6B.
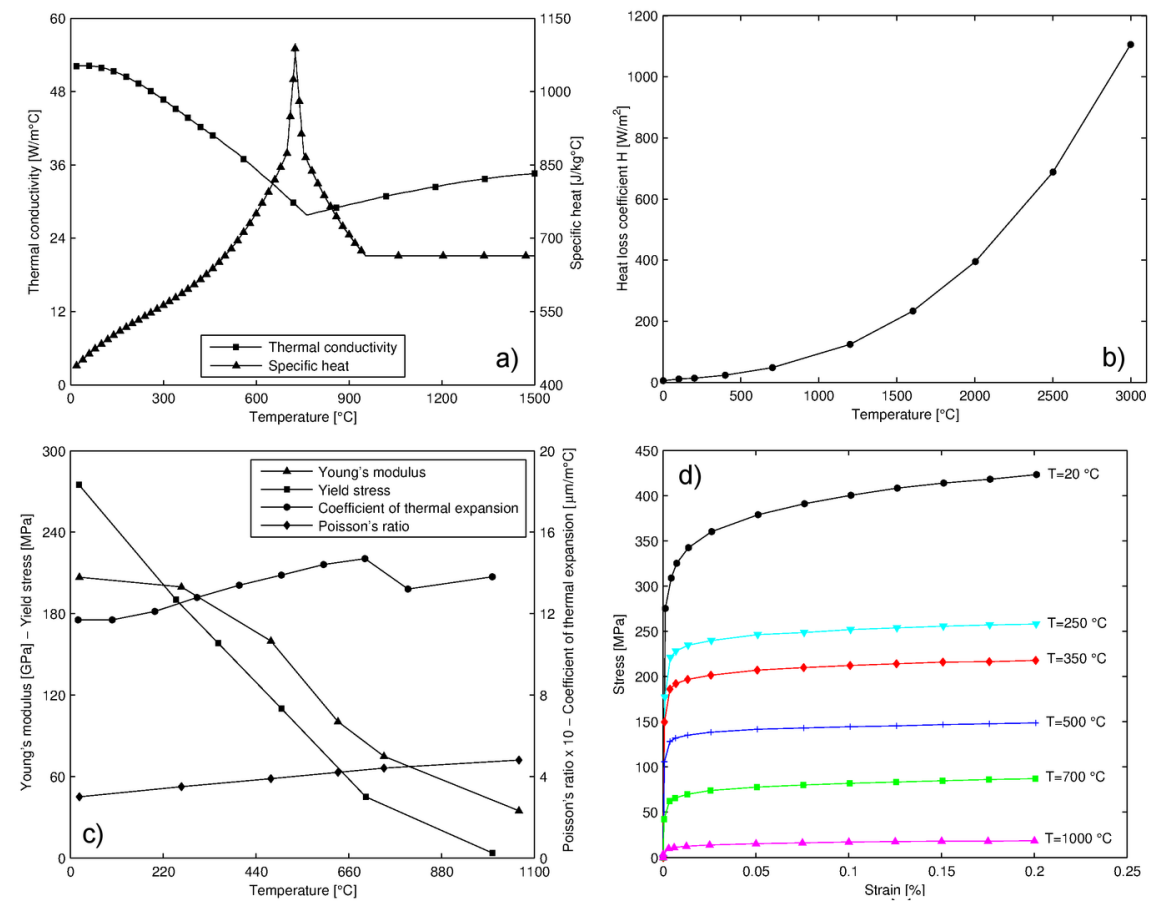

Figure 6 Thermal properties of material dependent on temperature A; variation of heat loss coefficient $H$ with temperature B; mechanical properties of material dependent on temperature $\mathrm{C}$; stress vs. strain curves with temperature D.

Mechanical analysis 
Temperature history achieved by the thermal analysis has been used in the mechanical analysis as thermal loads. An elasto-plastic material model, based on the von Mises yield criterion and isotropic strain hardening rule, has been considered, including the effects of the temperature on the material properties.

The stress-strain relations can be written as:

$[\delta \sigma]=\left[D^{\mathrm{ep}}\right] \bullet[\delta \varepsilon]-\left[C^{\mathrm{th}}\right] \bullet d T,(17)$

being:

$\left[D^{\mathrm{ep}}\right]=\left[D^{e}\right]+\left[D^{p}\right]$,

where: $\left[D^{e p}\right]$ is the total stiffness matrix; $\left[D^{e}\right]$ is the elastic stiffness matrix; $\left[D^{p}\right]$ is the plastic stiffness matrix and $\left[C^{t h}\right]$ is the thermal stiffness

Moreover, as aforementioned, a particular attention must be paid on the modelling of the symmetry boundary conditions. The transient thermal field generated by the welding process introduces several deformations inside the plates, leading to their interaction. Such interaction, which increases as the plate length increases (due to their rotation), has never been considered in the FE models proposed in literature ${ }^{17,21,22,31,34,36}$, by reducing this problem to a simple application of the symmetric boundary conditions. This results into too many approximations in the simulated residual stress-strain state, especially for long plates.

More in detail, when the first component is reactivated together with its symmetric boundary conditions, the plate starts to rotate due to the thermal loads, approaching, as a consequence, to the longitudinal symmetry plane. By progressively reactivating the components, up to the last components of the weld seam, the plate rotation may induce components to find themselves significantly beyond the longitudinal symmetry plane. Actually, such rotation is limited by the interaction of the plate with its counterpart. All these considerations suggest considering such phenomenon during the modelling, even if the modelling involves both plates.

Moreover, the plate rotation may lead also to convergence issues, especially as the plate length increases. The main reason of these convergence issues can be addressed to the activation of the symmetric constraints, which, under these conditions, would be applied to a more deformed plate (with respect to the real test case), leading to an increase of the residual stresses that can facilitate the lack of the analysis convergence.

In order to take into account the interaction of both plates in the proposed symmetric approach-based FE model, a row of finite elements (green finite elements in Figure 7) has been placed along the left side of the longitudinal symmetry plane (Figure 7A). This row of elements, of the same length as the plate (248 $\mathrm{mm})$, is made of 62 C3D8 finite elements and 252 nodes; an arbitrary width ( $x$ direction) and a height ( $z$ direction), slightly greater than the "root face" (Figure 1), simulates the interaction with the two plates, also in case of out-of-plane displacements. The mechanical material properties of these finite elements are the same of the plate. Concerning the boundary conditions applied on this row of elements, nodes placed on the interacting surface (face looking at the longitudinal symmetry plane) have been fully constrained.

In addition, the interaction between the plate and the work table, shown in Figure 1D, has been numerically replicated by modelling the work table as a rigid plane and by modelling the interaction between the plate and the rigid plane by means of a surface to surface contact algorithm. Moreover, in order to completely constrain the rigid motion of the plate, the translation along the $y$ and $z$ axes of the node $(x=0, y=0, z$ $=0)$ of the seam and the translation along the $z$ axis of the node $(x=0, y=248, z=0)$ have been fixed.

The interaction between the modelled plate and the row of elements has been defined through a surface to surface contact algorithm. Specifically, at the first load step the interaction involves all V-grove finite elements; subsequently, due to the progressive reactivation of "components" of the first weld pass together with the activation of the symmetric constraints along the $x$ direction (Figure 7 ), the interaction and the green finite elements belonging to the row of elements are removed progressively as well (Figure 7B), because not more useful. It must be highlighted that the simulation strategy does not increase significantly the computational costs. 
The translational constraints along the $x$ direction are progressively applied to the components nodes placed along the longitudinal symmetric plane during the weld pass. This type of boundary condition constrains also the rigid motion of the plate around $y$ and $z$ directions.

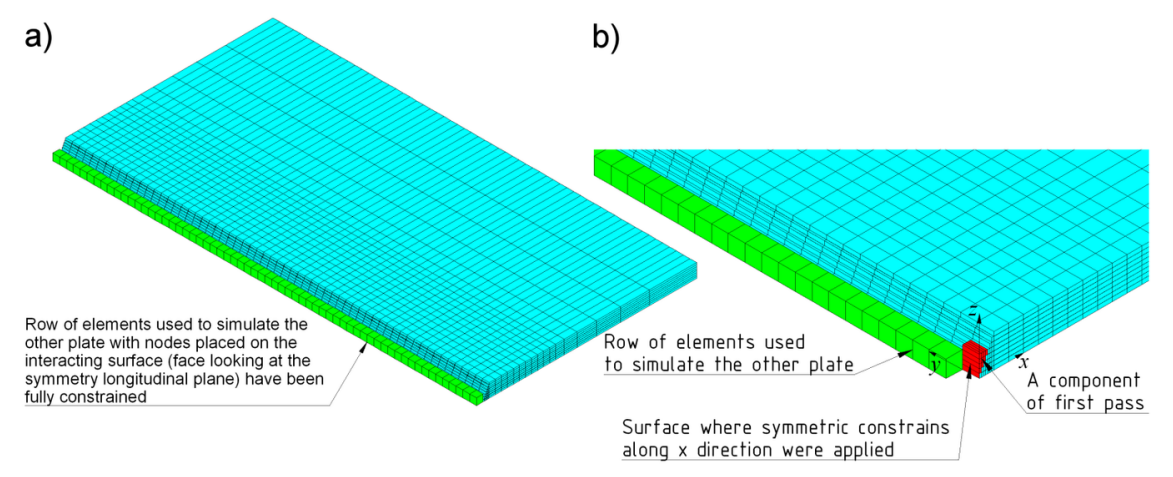

Figure 7 Row of elements (in green) simulating the left side plate A; suppression of the elements of row activation of the symmetric constraints along $x$ direction B.

Also the mechanical properties ${ }^{46,47}$ have been considered temperature dependent (Figure 6C). Moreover, since the structural analysis involves plastic deformation of the material, in this work, the hardening material model with von Mises yield criterion and the isotropic strain hardening rule have been assumed. The stress vs. strain curves, as a function of the temperature, are shown in Figure 6D.

Moreover, in steels, martensite is formed from austenite containing carbon atoms and, in view of the diffusionless nature of its formation, it ideally inherits the carbon atoms of the parent austenite. Therefore, while for some steel welded parts the solid-state austenite-martensite transformation during cooling has a significant influence on the residual stresses and distortion ${ }^{17,33,34,48,49,50,51}$, especially when the equivalent carbon content is high, for others (low equivalent carbon content), it may be neglected as well demonstrated by Cho et $\mathrm{al}^{52}$ and Deng. ${ }^{53}$ According to Cho et $\mathrm{al}^{52}$ and Deng ${ }^{53}$, the modelling of the transformation phase does not change the level of accuracy of the FE model, in terms of residual stresses and distortions prediction, when the welding process involves low carbon steels with low equivalent carbon content (about $\mathrm{C}_{\text {eq }}=0.23 \%$ ), as the steel used in this work. As a result, the solid-state transformation phase has not been considered in the modelling.

In order to evaluate the influence of the interaction between the plates, a second mechanical analysis has been carried out without considering the row of finite elements placed along the left side of the longitudinal symmetry plane (Figure 7) and by applying only the translational constraints along the $x$ direction to simulate the symmetry constraints.

3. Results and discussion

In this section, numerical results of the welding simulation are presented and compared with experimental ones, in order to assess the reliability of the used FE models.

\subsection{Thermal analysis}

The temperatures measured at six points by means of six thermocouples have been compared with the respective predicted ones.

Figure 8 shows the temperature distributions at the middle section of the plate along the transverse direction during the two passes, with the welding arc located at the middle of the welding path. It is possible to appreciate a good agreement between numerical and experimental results, with the numerical curves that well estimate the experimental measurements during both welding passes. 

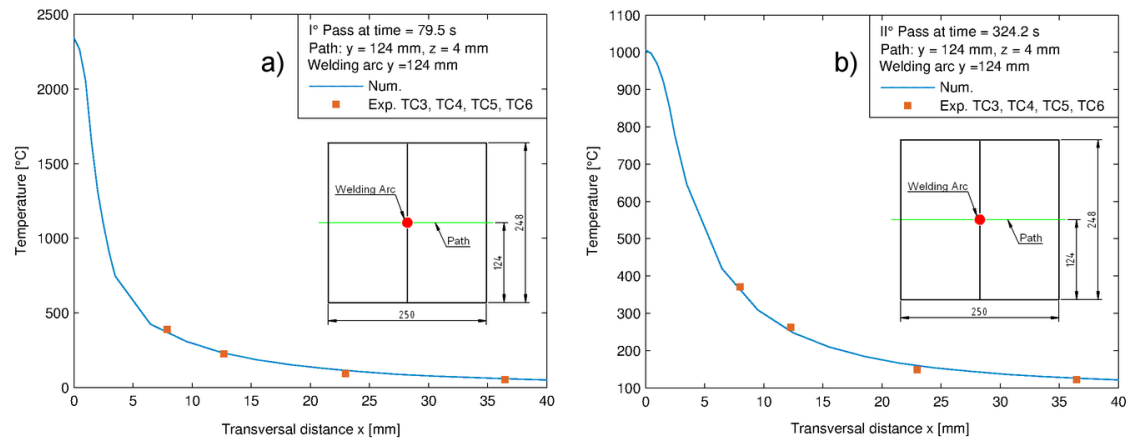

Figure 8 Temperature distributions at the middle section of the plate along transversal direction during the first (A) and the second (B) passes.

The experimental-numerical thermal histories are shown in Figure 9, for the thermal cycles recorded in correspondence of the thermocouples TC1 and TC2, and in Figure 10 for thermal cycles recorded from thermocouples from TC3 to TC6.
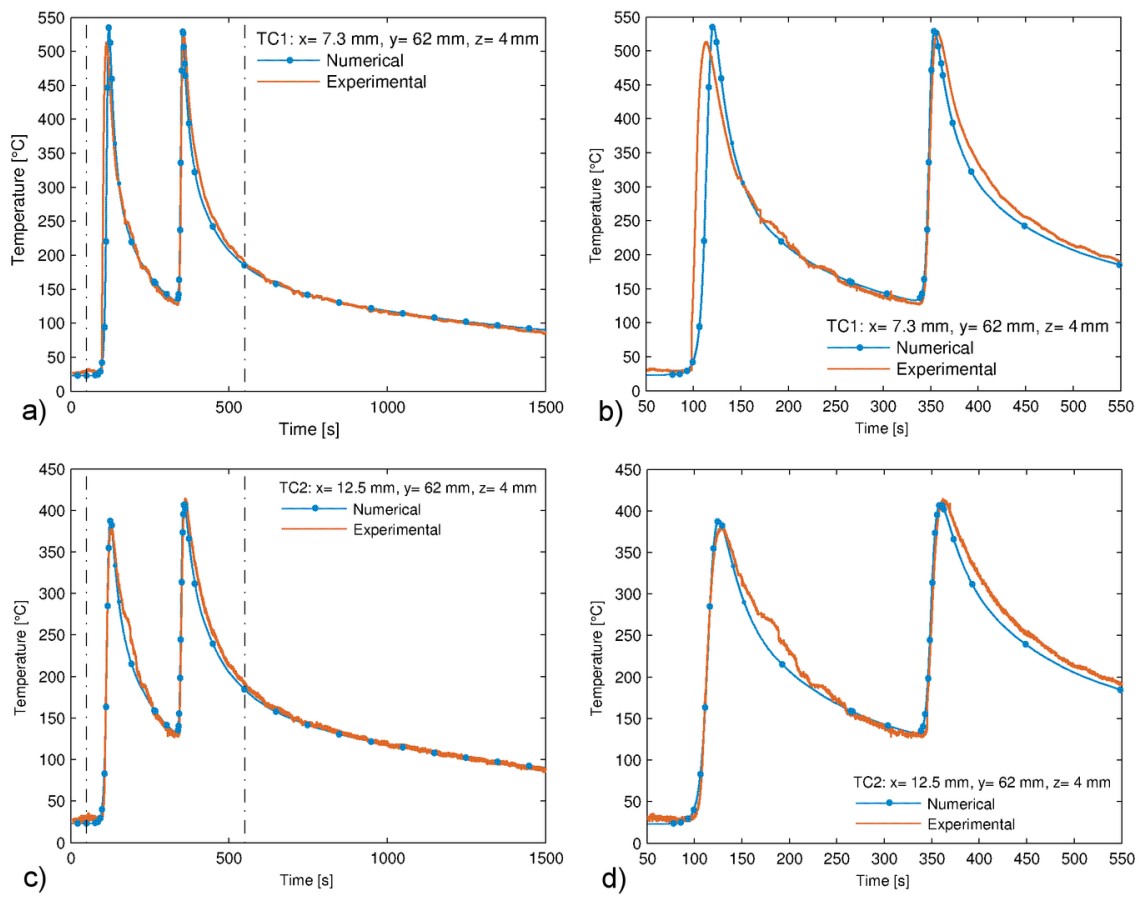

Figure 9 Thermal histories in correspondence of thermocouples: A, TC1; B, focus on TC1; C, TC2 and D, focus on TC2.

Figure 9 shows a good agreement between numerical and experimental results as general trend. In order to better highlight the differences between numerical and experimental curves, thermal histories curves at TC1 and TC2 have been cut at a time of $550 \mathrm{~s}$ and reported in Figures 9B and 9D, respectively. According to Figures $9 \mathrm{~A}$ and 9B, the FE model provides, in correspondence of $\mathrm{TC} 1$, a small over-estimation of about $23{ }^{\circ} \mathrm{C}$ in the first peak value, corresponding to the first pass. This can be due to a displacement of the thermocouple within the plate hole, occurred during the first pass, leading to a not perfect contact between the thermocouple and the plate. This difference cannot be found during the second pass because the correct 
position of all thermocouples was checked at the end of the first pass. Moreover, according to Figure 9B, a time shift can be observed between numerical and experimental data. Such disagreement can be attributed to the welding speed, not perfectly constant along the whole weld seam, but, in proximity of thermocouple TC1, faster than the value reported in Table 3. As matter of the fact, the welding speed reported in Table 3 has been calculated as the ratio of the time spent for the first pass to the length of the weld seam.

Figure 10 shows the comparison of the numerical results with the experimental ones in correspondence of thermocouples located at the middle section of the plate during the whole process. Also here, in order to highlight the differences between numerical and experimental results, curves have been cut at $550 \mathrm{~s}$ and reported in Figures 10B, 10D, 10F and 10H. Excluding the initial experimental values of the curves, which are affected by high noise due to the electrical shock at the beginning of the welding process, it can be stated that the experimental results are in good agreement with the numerical ones. It can be observed that the FE model provides a small over-estimation of about $17{ }^{\circ} \mathrm{C}$ in correspondence of the second peak, during the second pass, at TC3 (Figure 10B), while there are slight differences in the peak values during the first pass at TC4 (Figure 10D) and TC6 (Figure 10H), characterized by an under-estimation of the numerical results. However, these differences are lower than about $5 \%$. 

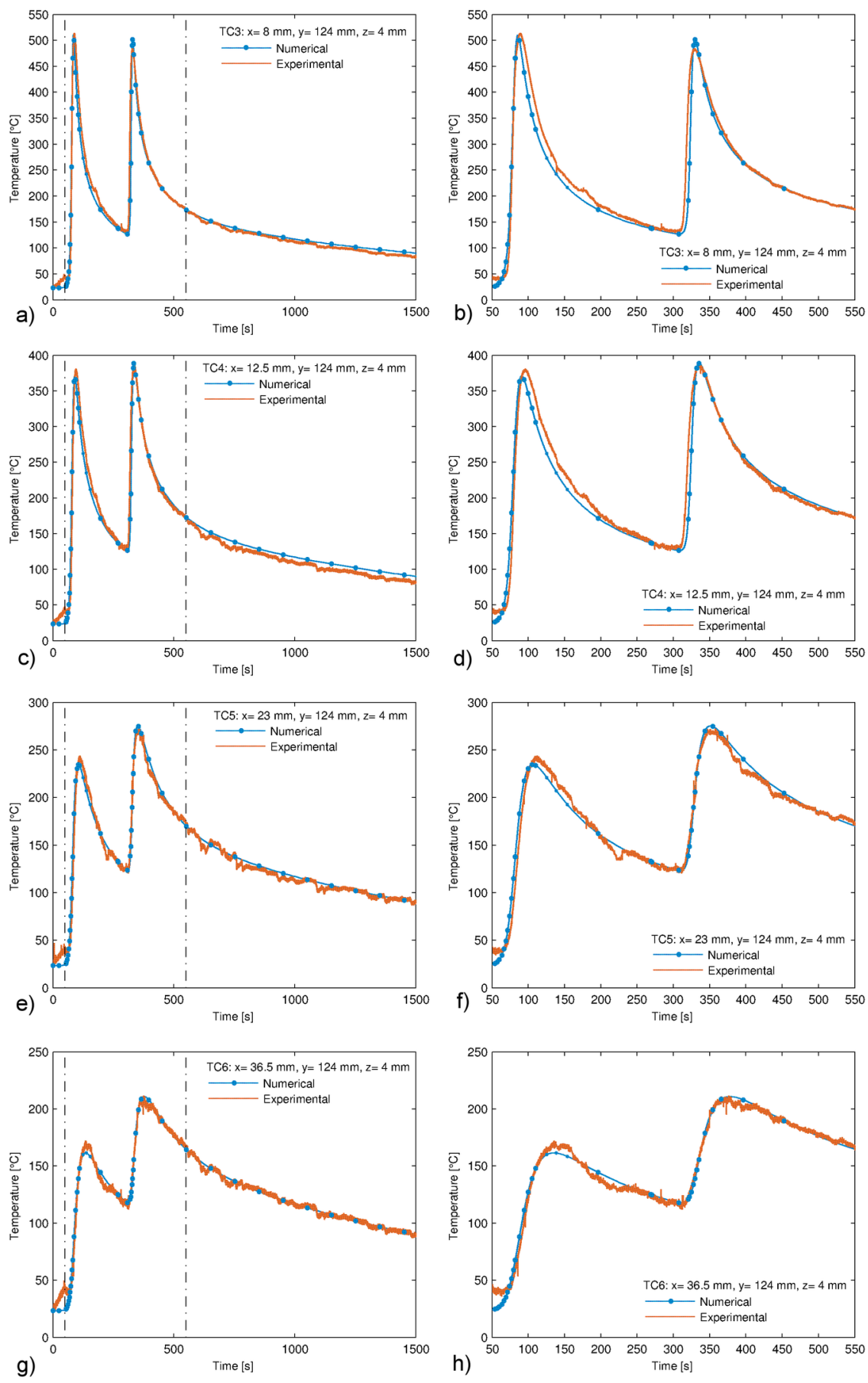

Figure 10 Thermal histories in correspondence of thermocouples: A, TC3; B, focus on TC3; C, TC4; D, focus on TC4; E, TC5; F, focus on TC5; G, TC6 and H, focus on TC6.

Figures 11A and 11B show the temperature distributions during the first and second passes at welding times of $t=66.67 \mathrm{~s}$ and $t=315 \mathrm{~s}$ respectively. The centre of the welding arc at these times is at the position of $x$ $=0 \mathrm{~mm}$ and $y=104 \mathrm{~mm}$. As it can be seen from the figures, the peaks of temperature around the welding arc, at the two instants, are calculated to be about $2460{ }^{\circ} \mathrm{C}$ and $2116{ }^{\circ} \mathrm{C}$, respectively, suggesting that the 
material is melted in the fusion zone. High temperatures are present nearby the fusion zone (FZ), defining the heat affected zone (HAZ).

During the first pass, the thermal gradients are very steep in the proximity of the heat source, while they decrease during the second pass; furthermore, near the welding line, the distance between the isotherms increases as the cooling rate decreases and the welding pool also presents a very small area in front of the welding arc.
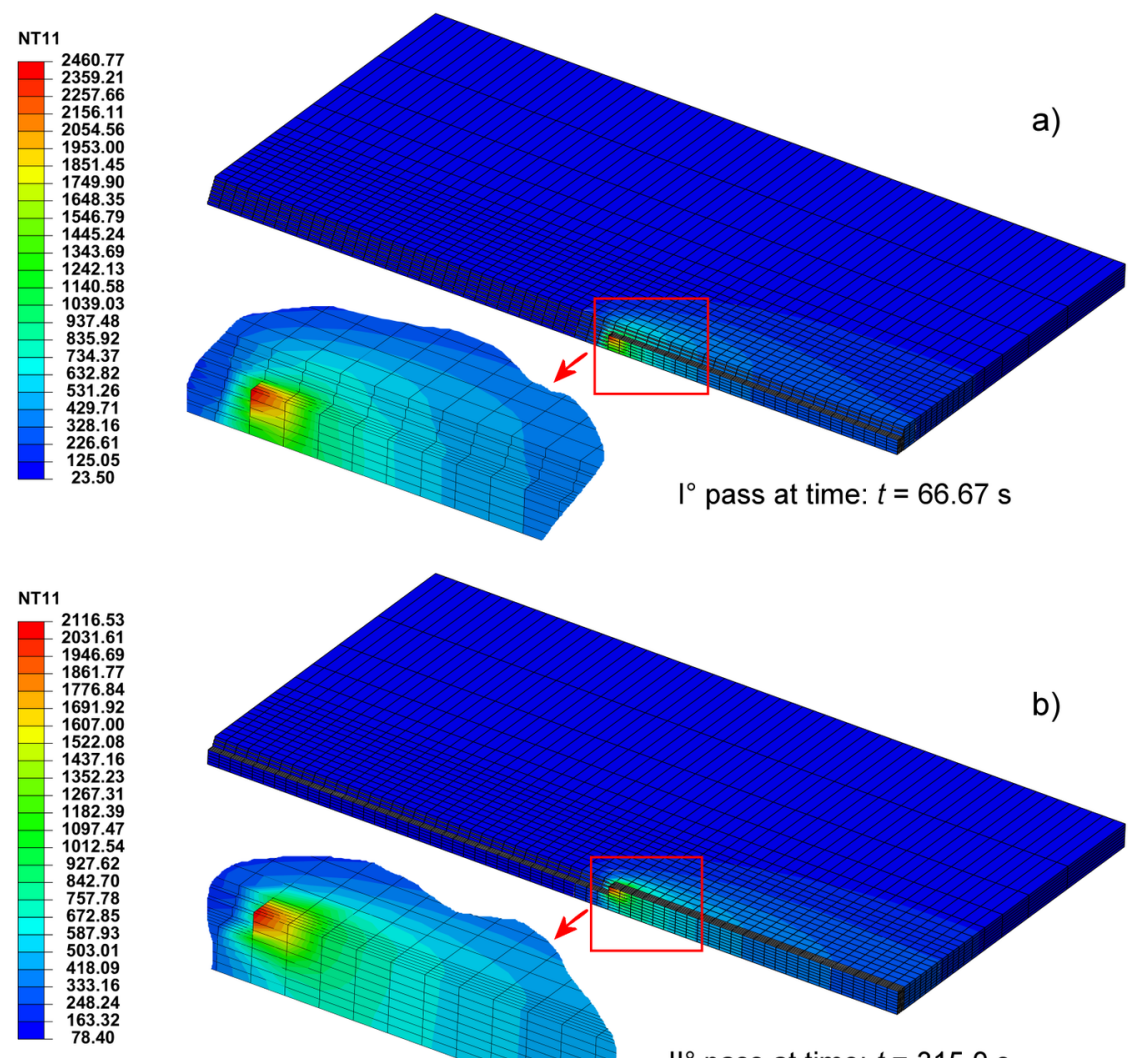

$I^{\circ}$ pass at time: $t=315.0 \mathrm{~s}$

Figure 11 Temperature distributions $\left[{ }^{\circ} \mathrm{C}\right]$ during: A, I pass at time $t=66.67 \mathrm{~s}$ and $\mathrm{B}$, II pass at time $t=315$ s.

Figure 12 compares the experimental and the predicted FZ and HAZ. As shown in this figure, the geometry and shape of both weld seam and HAZ are well numerically replicated. As matter of the fact, the HAZ can be defined as the section reaching a temperature higher than $727^{\circ} \mathrm{C}$ during the welding process. ${ }^{54}$ 

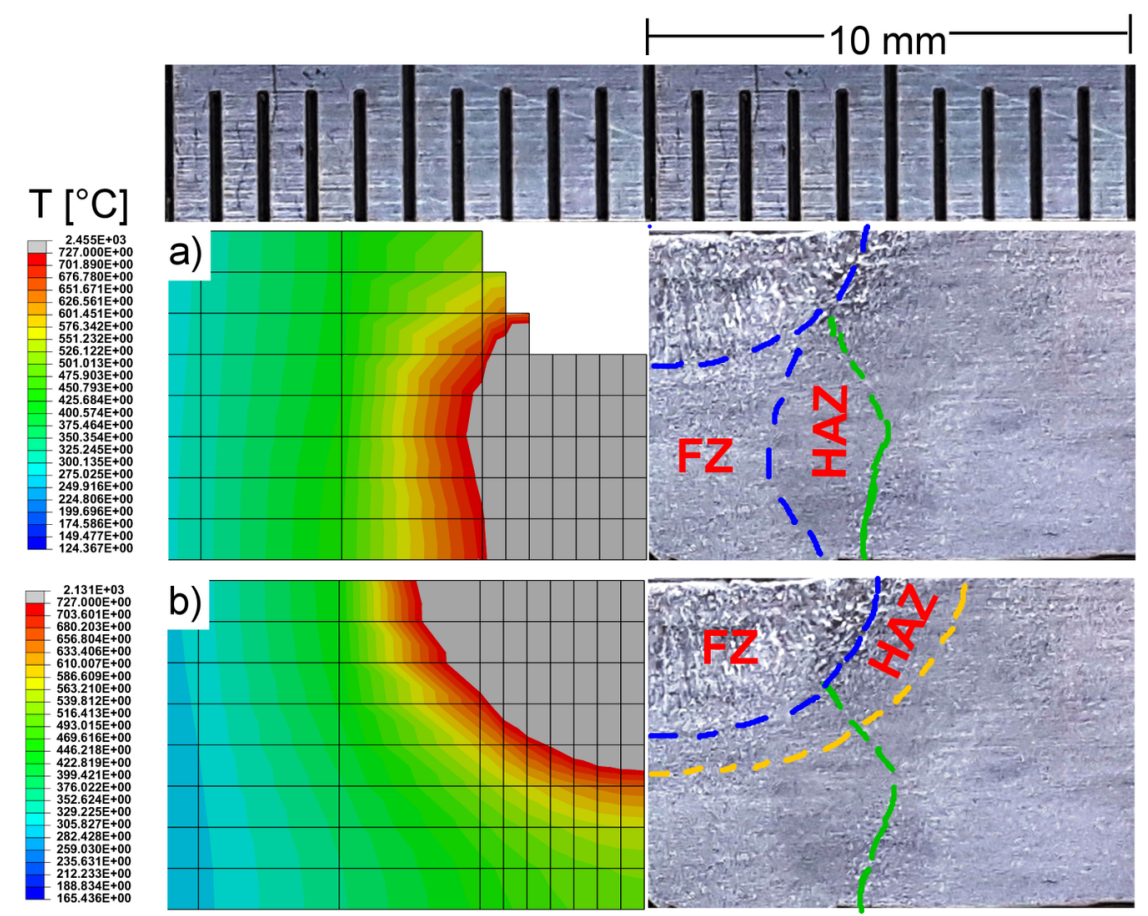

Figure 12 Numerical-experimental comparison of HAZ, during the first (A) and the second pass (B).

By comparing the numerical results with the experimental ones, it is possible to state that the used methodology is suitable to predict very accurately the temperatures distribution in the welded joint, without the need to perform a tuning process to opportunely calibrate the heat source. ${ }^{17,27,32,33,34,44}$

\subsection{Mechanical analysis}

The longitudinal residual stresses $\sigma_{\psi}$, induced from the longitudinal expansion and contraction of the material during the welding process, along the $x$-direction at the midsection $(y=124 \mathrm{~mm}, z=4 \mathrm{~mm})$ are shown in Figure 13A (line with marker). The self-equilibrium of the weldment is such that the tensile and compressive residual stresses are present at the weld seam and away from the welding line respectively. High tensile residual stresses are present in correspondence of the zones nearby the Welding Centre Line (WCL), due to the contraction resistance of the material as the cooling phase begins. Then, they decreased to zero, as the distance from the (WCL) increases, becoming compressive for the zones far from the weld seam. The transversal residual stresses $\sigma_{\xi}$ along the $x$-direction in the midsection $(y=124 \mathrm{~mm}, z=4 \mathrm{~mm})$ are shown in Figure 13B. Tensile residual stresses are present in correspondence of the zones nearby the (WCL). Subsequently, they decreased as the distance from the (WCL) increased, up to 0, almost. 

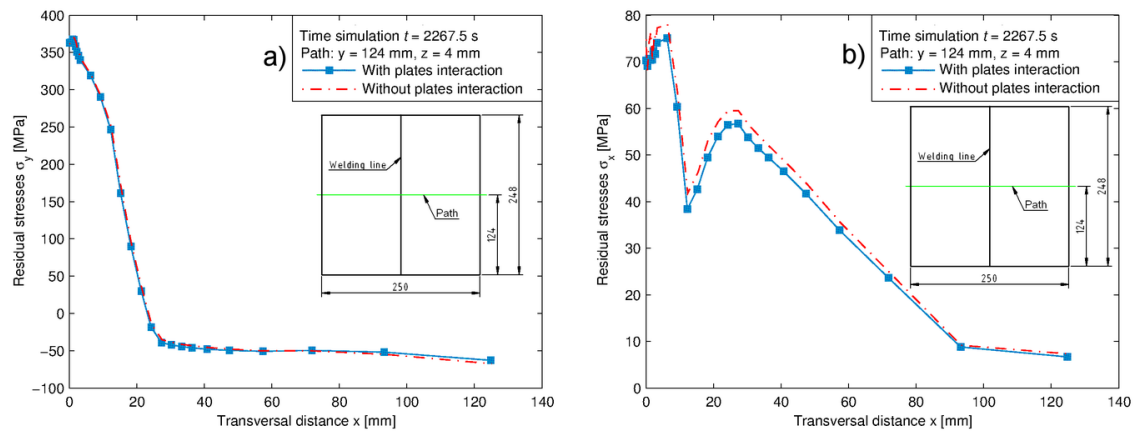

Figure 13 Comparison of the longitudinal residual stresses distribution $\sigma \psi(\mathrm{A})$ and the transversal residual stresses distribution $\sigma \xi(\mathrm{B})$, along $x$-direction at midsection $(y=250 \mathrm{~mm}, z=4 \mathrm{~mm})$ achieved by the $\mathrm{FE}$ models considering and not the plates interaction.

In Figure 14 the numerical displacements, $u_{z}$, predicted in correspondence of the path $y=248 \mathrm{~mm}, z=0$ $\mathrm{mm}$ (green line of Figure 14A) and in corresponding of the path $x=125 \mathrm{~mm}, z=0 \mathrm{~mm}$ (red line of Figure 14B), achieved by imposing the temperatures distribution predicted by the thermal analysis as thermal loads in the mechanical analysis, are compared with the experimental ones measured by means of a Coordinate Measuring Machine(CMM) shown in Figure 2C. According to Figure 14, the numerical results are in good agreement with experimental ones; therefore, it is possible to state that the numerical technique, used for the mechanical analysis, can predict with a high level of accuracy the distortions in the welded joint.
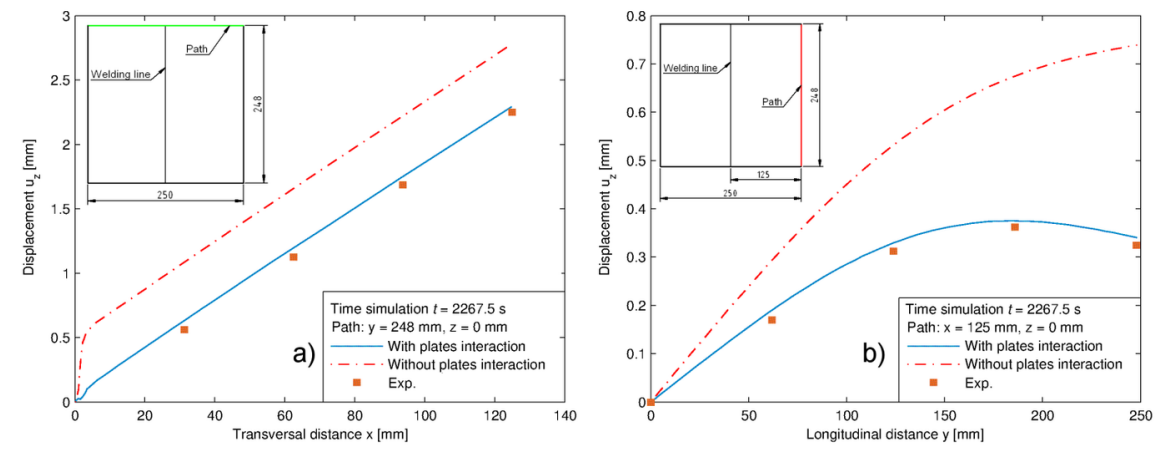

Figure 14 Comparison of the experimental distortions with those predicted by the FE models considering and not the plates interaction: A, along the path at $y=248 \mathrm{~mm}$ and $z=0 \mathrm{~mm}$ and $\mathrm{B}$, along the path at $x$ $=125 \mathrm{~mm}$ and $z=0 \mathrm{~mm}$.

As aforementioned, in order to appreciate the effects provided by the modelling of the plates interaction during the welding process, the predicted residual stresses and distortions have been compared with those provided by the simulation performed by deactivating the plates interaction (Figures 13 and 14).

According to Figure 13A, as expected, it can be noticed that the longitudinal residual stresses distribution seems to be unaffected by the plates interaction. As matter of the fact, plates have not been constrained along the longitudinal direction. Contrary, the plates interaction affects the transversal residual stresses distributions, because of the plates rotation during the welding process. Residual stresses appear to be slightly higher (Figure 13B) for the model that does not consider the plates interaction and they are expected to increase for longer plates, because of their rotation.

If the effects of the plates interaction on residual stresses distribution may be considered negligible for the selected test case, a similar consideration cannot be done in terms of distortions distribution. According to 
Figure 14, the predicted distortions distribution appears to be sensibly higher and far from the experimental data for the FE model that does not consider the plates interaction. As a result, the plates interaction plays a key-role in the modelling of the welding process induced distortion.

5. conclusions

This paper presents a novel numerical model, based on the Finite Element method, for the simulation of a welding process aimed to make a two-passes V-groove butt weld joint. In order to evaluate the residual stresses, a 3D non-linear thermo-mechanical analysis has been carried out. The thermo-mechanical response of the joint has been simulated by using an uncoupled approach. Specifically, the "element birth and death" technique has been used to simulate the welding filler during the welding process. The originality of the proposed technique has to be found in the simulation of the interaction occurring between the two plates during the welding process, never considered in literature when the problem is faced through a symmetrical approach. As a result, it was possible to predict more accurately the residual stresses affecting the joint, caused by the thermal distortions which lead the plates to rotate. The proposed modelling technique appears to be fundamental for long plates, since the plates interaction becomes not negligible as the plate length increases. Specifically, in order to save the computational costs, only a plate and half seam have been modelled. As a result, in order to simulate the plates interaction, a row of finite elements has been placed along the left side of the longitudinal symmetry plane. This approach allows predicting the residual stresses also for long joined plates, which require a higher number of nodes and elements and, consequently, a higher time analysis. A surface to surface contact algorithm has been considered between the half seam and the finite elements row.

Moreover, differently from the literature, the heat amount is supplied to the finite elements as a volumetric generation of the internal energy, allowing overcoming the time-consuming calibration phase required by the Goldak's model, commonly adopted in literature.

The reliability of the FE model has been shown by assessing the predicted results, in terms of temperatures distribution and joint distortion, against the results provided by an experimental test. Temperatures distribution has been measured during the welding process by using six thermocouples placed at different locations nearby the weld bead; welding distortions were measured by means of a Coordinate Measuring Machine. A good agreement has been found between numerical and experimental results, showing the effectiveness of the proposed FE modelling technique.

References

[1] Gunnert R. Residual Welding Stressed. Almqvist \& Wiksell. Stockholm; 1955.

[2] Connor LP. Welding Handbook. 8th ed. American Welding Society. Miami, Fl; 1987.

[3] Masubuchi K. Analysis of welded structures. $1^{\text {st }}$ ed. Pergamenon Press. Oxford, UK; 1980.

[4] Barsoum Z, Barsoum I. Residual stress effects on fatigue life of welded structures using LEFM. Eng Fail Anal 2009;16:449-467.

[5] Citarella R, Carlone P, Lepore M, Sepe R. Hybrid technique to assess the fatigue performance of multiple cracked FSW joints. Eng Fract Mech 2016;162:38-50.

[6] Sepe R, Wiebesiek J, Sonsino CM. Numerical and experimental validation of residual stresses of laserwelded joints and their influence on the fatigue behaviour. Fatigue Fract Eng Mater Struct. 2019;1-16.

[7] Mackerle J. Finite element analysis and simulation of welding: a bibliography (1976-1996). Medel Simul Mater Sc 1996;4:501-533.

[8] Dong P. Residual stresses and distortions in welded structures: A perspective for engineering applications. Sci Technol Weld Joi 2005;10:389-398. 
[9] Satyambau K, Ramachandrani N. Feasibility studies on the modelling and evaluation of residual stresses in arc welded butt joint. In Proceedings of ESDA2006 2006, Turin, Italy.

[10] Norton JT. X-ray determination of residual stress. Material Evaluation; 1973.

[11] Noyan IC, Cohen JB. Residual stress measurement by diffraction and interpretation. Springer. New York; 1987.

[12] Park MJ, Yang HN, Jang DY, Kim JS, Jin TE. Residual stress measurement on welded specimen by neutron diffraction. J Mater Process Tech 2004;155-156:1171-1177.

[13] Owen RA, Preston RV, Withers PJ, Shercliff HR, Webster PJ. Neutron and synchrotron measurement on welded specimen by neutron diffraction. Mater Sci Eng A 2003;346:159-167.

[14] Joseph A, Rai SK, Jayakumar T, Murugan N. Evaluation of residual stresses in dissimilar weld joitns. Int J Pres Ves Pip 2005;82:700-705.

[15] Bouchard PJ, George D, Santisteban JR, Bruno G, Dutta M, Edwards L, Kingston E, Smith DJ. Measurement of the residual stresses in a stainless steel pipe girth weld containing long and short repairs. Int J Pres Ves Pip 2005;82:299-310.

[16] Schajer GS. Hole-drilling residual stress profiling with automated smoothing. Transaction of the ASME 2007;129:pp. 440-445.

[17] Mollicone P, Camilleri D, Gary TGF, Comlekci T. Simple thermo-elastic-plastic models for welding distortion simulation. J Mater Process Tech 2006;176:77-86.

[18] Lindgren LE. Finite element modelling and simulation of welding part 1: increased complexity. J Therm Stresses 2001;24:141-192.

[19] Lindgren LE. Finite element modelling and simulation of welding. Part 2: improved material modelling. J Therm Stresses 2001;24:195-231.

[20] Lindgren LE. Finite element modelling and simulation of welding. Part 3: efficiency and integration. J Therm Stresses 2001;24:305-334.

[21] Teng TL, Chang PH, Tseng WC. Effect of welding sequences on residual stresses. Comput Struct 2003;81:273-286.

[22] Chang PH, Teng TL. Numerical and experimental investigations on the residual stresses of the buttwelded joints. Comp Mater Sci 2004;29:511-522.

[23] Armentani E, Esposito R, Sepe R. Finite element analysis of residual stresses on butt welded joints. In Proceedings ESDA2006 2006, Turin, Italy.

[24] Armentani E, Esposito R, Sepe R. The effect of thermal properties and weld efficiency on residual stresses in welding. J Achiev Mater Manuf Eng 2007;20:319-322.

[25] Armentani E, Esposito R, Sepe R. The influence of thermal properties and preheating on residual stresses in welding, International Journal of Computational Materials Science and Surface Engineering 2007;1(2):146162.

[26] Armentani E, Pozzi E, Sepe R. Finite element simulation of temperature fields and residual stresses in butt welded joints and comparison with experimental measurements. In Proceedings ESDA2014 2014, Copenhagen, Denmark.

[27] Kermanpur A, Shamanian M, Yeganeh V.E. Three-dimensional thermal simulation and experimental investigation of GTAW circumferentially butt-welded Incoloy 800 pipes. J Mater Process Tech 2008;199:295303. 
[28] Sepe R, Armentani E, Lamanna G, Caputo F. Evaluation by FEM of the influence of the preheating and post-heating treatments on residual stresses in welding. Key Eng Mat 2015;628:93-96.

[29] Sepe R, Laiso M, De Luca A, Caputo F. Evaluation of residual stresses in butt welded joint of dissimilar material by FEM. Key Eng Mat 2017;754:268-271.

[30] Mondal AK, Biswas P, Bag S. Prediction of welding sequence induced thermal history and residual stresses and their effect on welding distortion. Weld World 2017;61:711-721.

[31] Hashemzadeh M, Chen BQ, Soares CG. Evaluation of multi-pass welding-induced residual stress using numerical and experimental approach. Ships Offshore Struc 2018;13.

[32] Tsirkas SA. Numerical simulation of the laser welding process for the prediction of temperature distribution on welded aluminium aircraft components. Opt Laser Technol 2018;100:45-56.

[33] Choi J, Mazumder J. Numerical and experimental analysis for solidification and residual stress in the GMAW process for AISI 304 stainless steel. J Mater Sci 2002;37:2143-2158.

[34] Tsirkas SA, Papanikos P, Kermanidis T. Numerical simulation of the laser welding process in butt-joint specimens. J Mater Process Tech 2003;134: 59-69.

[35] Cho JR, Lee BY, Moon YH, Van Tyne CJ. Investigation of residual stress and post weld heat treatment of multi-pass welds by finite element method and experiments. J Mater Process Tech 2004;155-156:1690-1695.

[36] Gery D, Long H, Maropoulos P. Effects of welding speed, energy input and heat source distribution on temperature variations in butt joint welding. J Mater process tech 2005;167:393-401.

[37] Citarella R, Carlone P, Lepore M, Palazzo G. FEM-DBEM Investigation of the Influence of Process Parameters on Crack Growth in Aluminum Friction Stir Welded Butt Joints. Key Eng Mat 2013;554557:2118-2126.

[38] Citarella R, Carlone P, Sepe R, Lepore M. DBEM crack propagation in friction stir welded aluminum joints. Adv Eng Software 2016;101:50-59.

[39] Mochizuki M, Hayashi M, Hattori T. Numerical analysis of welding residual stress and its verification using neutron diffraction measurement. Transaction of the ASME 2000;122:98-103.

[40] Vilaça P, Quintino L, dos Santos JF. iSTIR - Analytical thermal model for friction stir welding. J Mater Proc Tech 2005;162:452-465.

[41] Binda B, Capello E, Previtali B. A semi-empirical model of the temperature field in the AISI 304 laser welding. J Mater Process Tech 2004;155-156:1263-1241.

[42] Goldak JA, Chakravarti A, Bibby MJ. A New Finite Element Model for Welding Heat Sources. Trans AIME 1984;15: 299-305.

[43] Cengl YA. Heat Transfer. New York. Mc Graw-Hill Companies; 2003. ISBN 0-07-245893-3.

[44] Bradáč J. Calibration of heat source model in numerical simulations of fusion welding. Machines Technologies Materials 2016;11.

[45] Lindgren LE. Computational welding mechanics. Thermomechanical and microstructural simulations. Woodhead Publishing, Cambridge; 2007.

[46] Boyer HE, Gall TL. Metals Handbook, American Society for Metals, Materials Park, OH; 1985.

[47] Holt JM. Structural Alloys Handbook, CINDAS/Purdue University, West Lafayette, IN; 1996.

[48] Deng D, Murakawa H. Prediction of welding residual stress in multi-pass butt-welded modified 9Cr-1Mo steel pipe considering phase transformation effects, Comput Mater Sci 2006; 37: 209-219. 
[49] Ramos HME, Tavares SMO, de Castro PMST. Numerical modelling of welded T-joint configurations using SYSWELD, J Mater Sci Technol 2018; 30: 6-15.

[50] Börjesson L, Lindgren LE. Simulation of Multipass Welding With Simultaneous Computation of Material Properties, J Eng Mater-T ASME 2001; 123: 106-111.

[51] Lima TR, Tavares SMO, de Castro PMST. Residual stress field and distortions resulting from welding processes: numerical modelling using Sysweld, Ciência \& Tecnologia dos Materiais 2017; 29 (1): e56-e61.

[52] Cho SH, Kim JW. Analysis of residual stress in carbon steel weldment incorporating phase transformations, Sci Technol Weld Joi 2002; 7 (4): 212-216.

[53] Deng D. FEM prediction of welding residual stress and distortion in carbon steel considering phase transformation effects, Mater. Des 2009; 30:359-366.

[54] Pyo C. Kim J. Kim J. Estimation of Heat Source Model's Parameters for GMAW with Non-linear Global Optimization-Part I: Application of Multi-island Genetic Algorithm. Metals 2020; 10, 885.

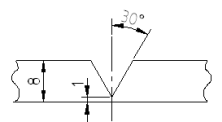

a)

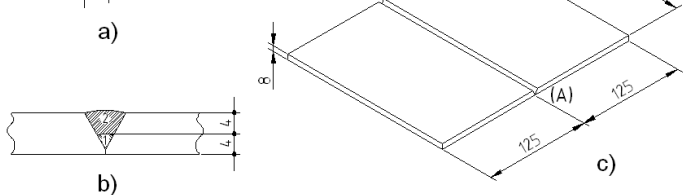

b)
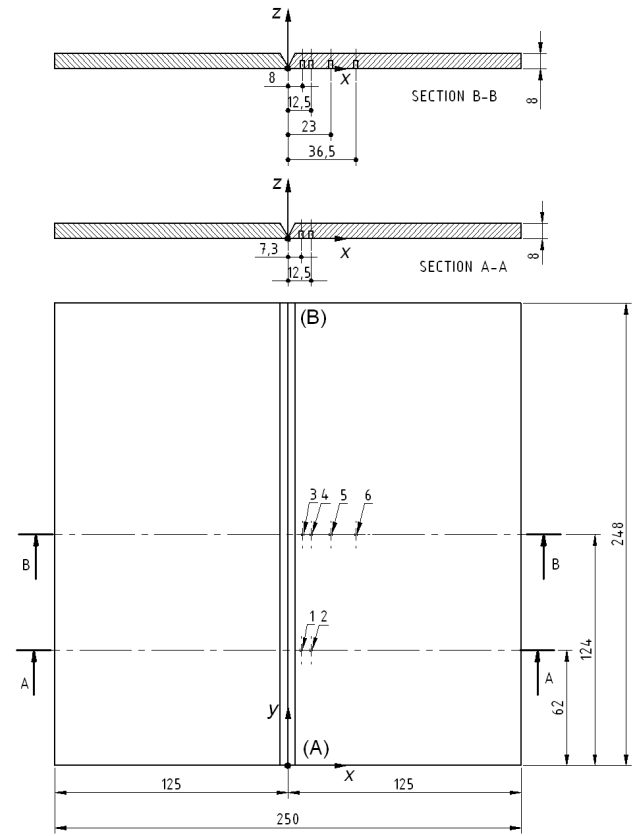

a)

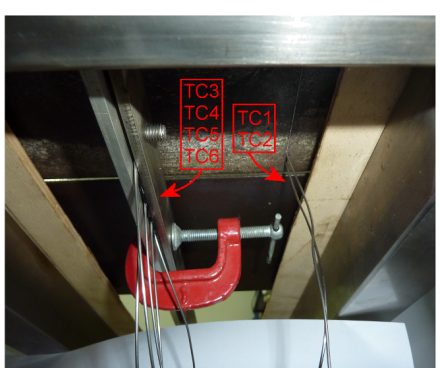

b)

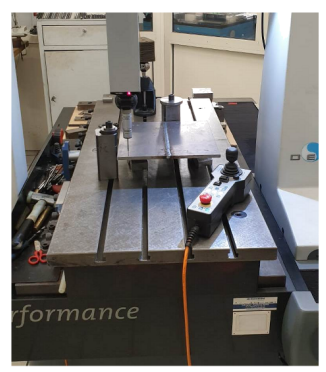

c) 

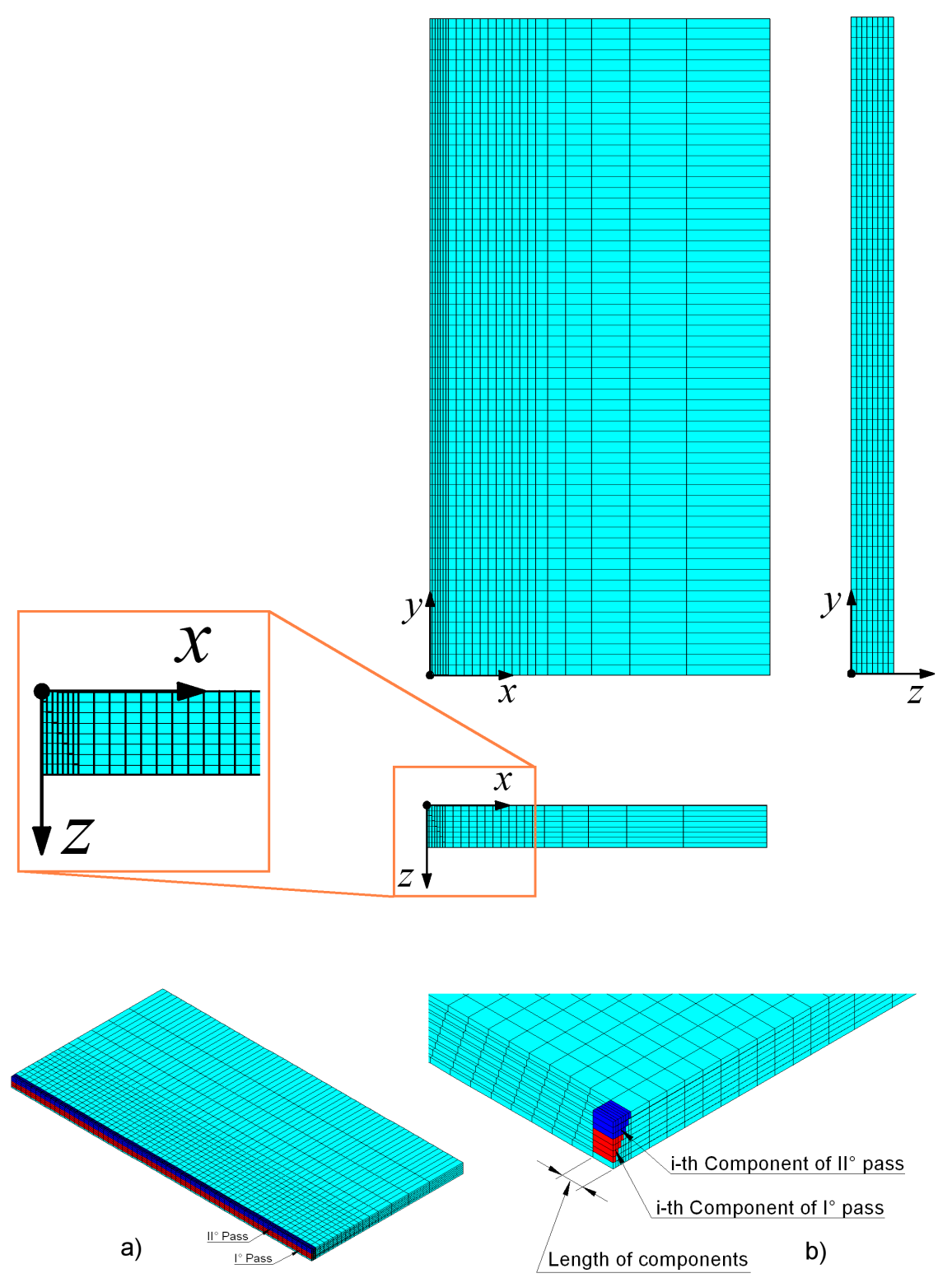

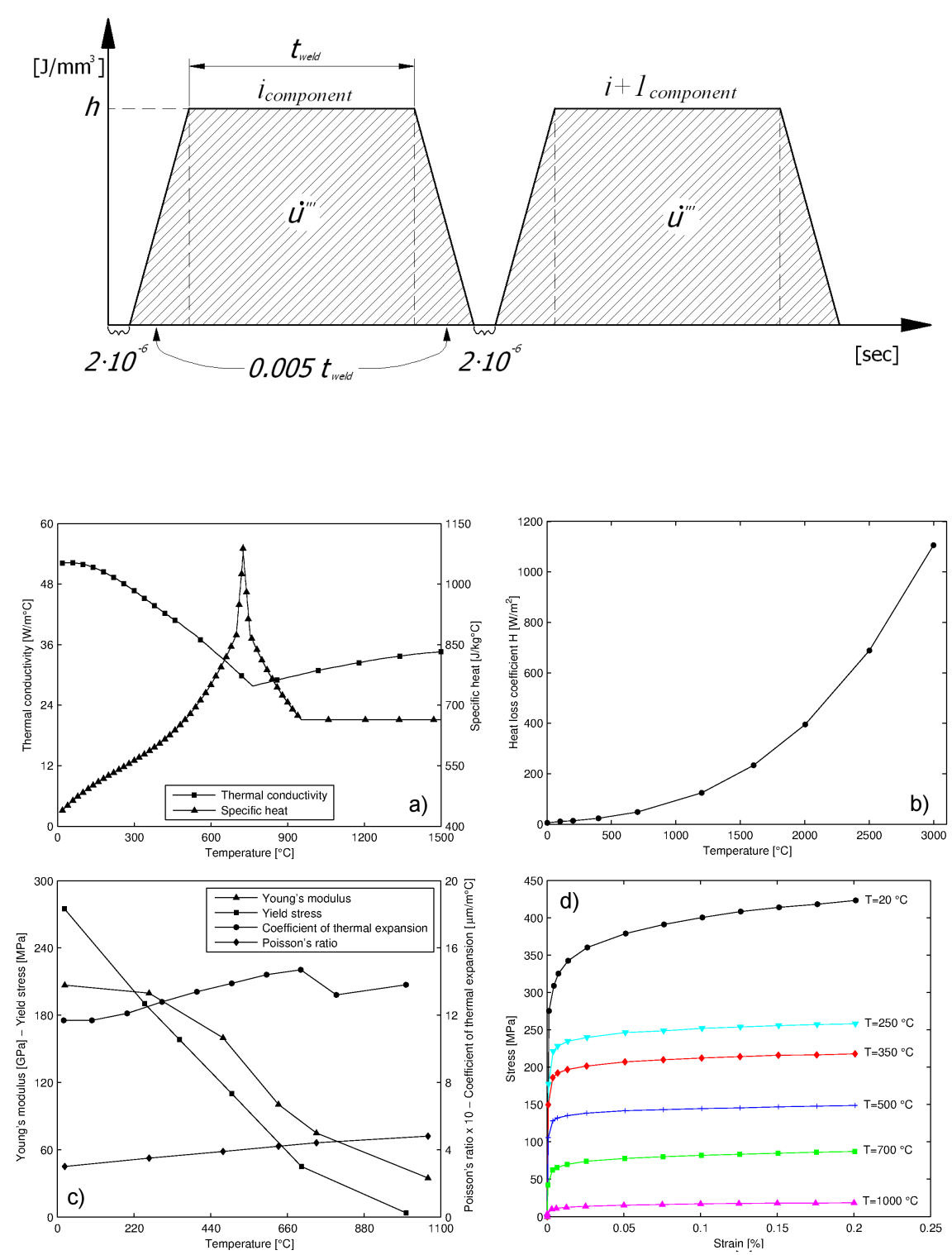

a)

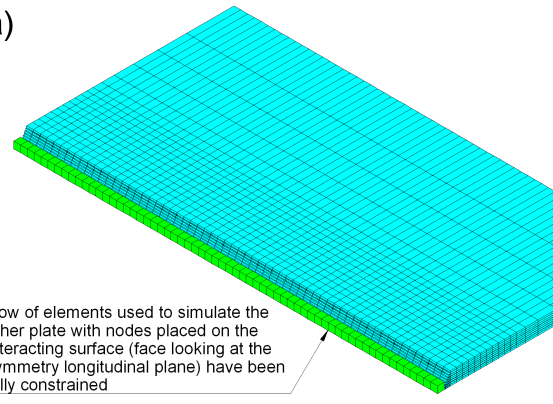

b)

Row of elements used
to simulate the other plate of first pass Surface where symmetric constrains along $x$ direction were applied 

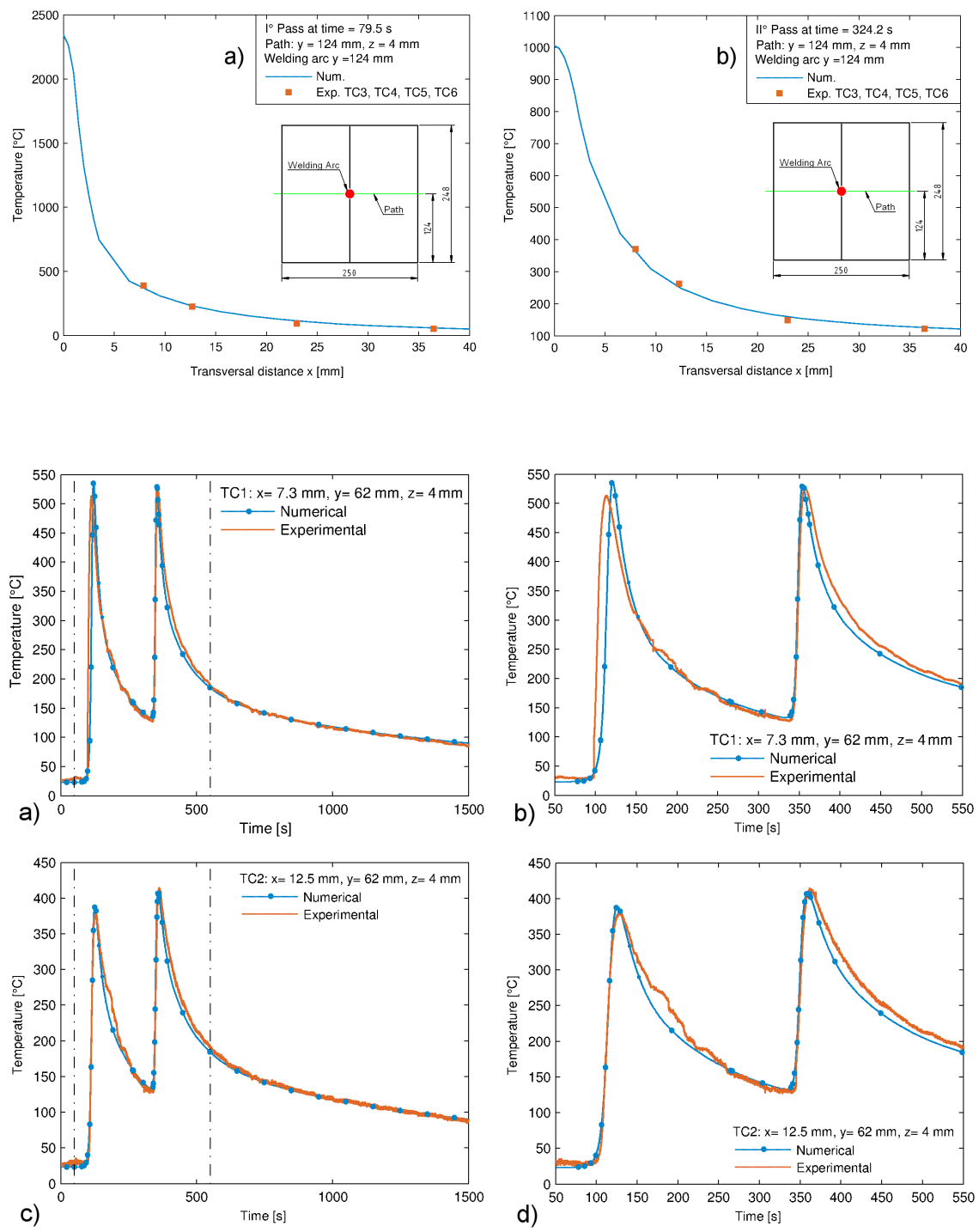

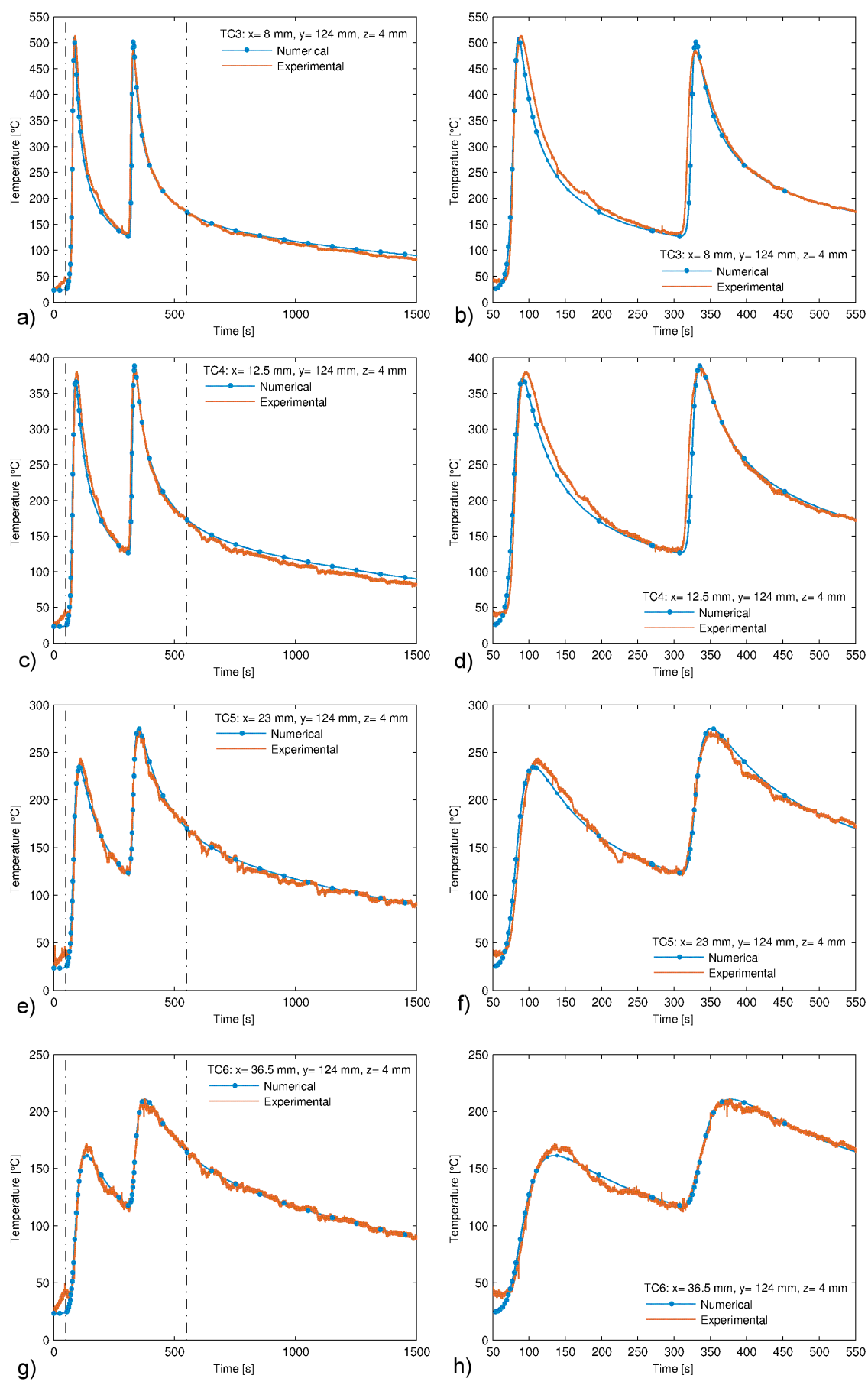

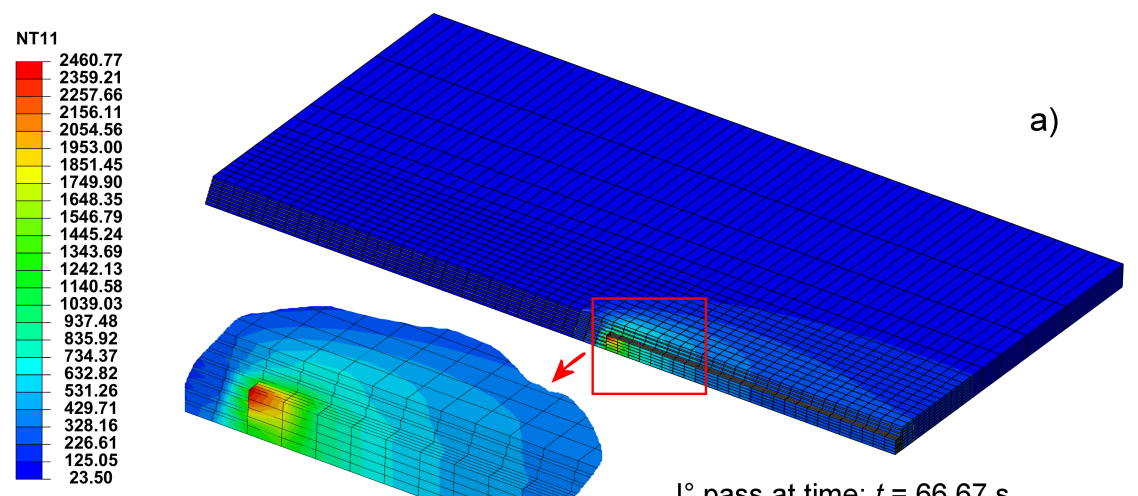

$I^{\circ}$ pass at time: $t=66.67 \mathrm{~s}$
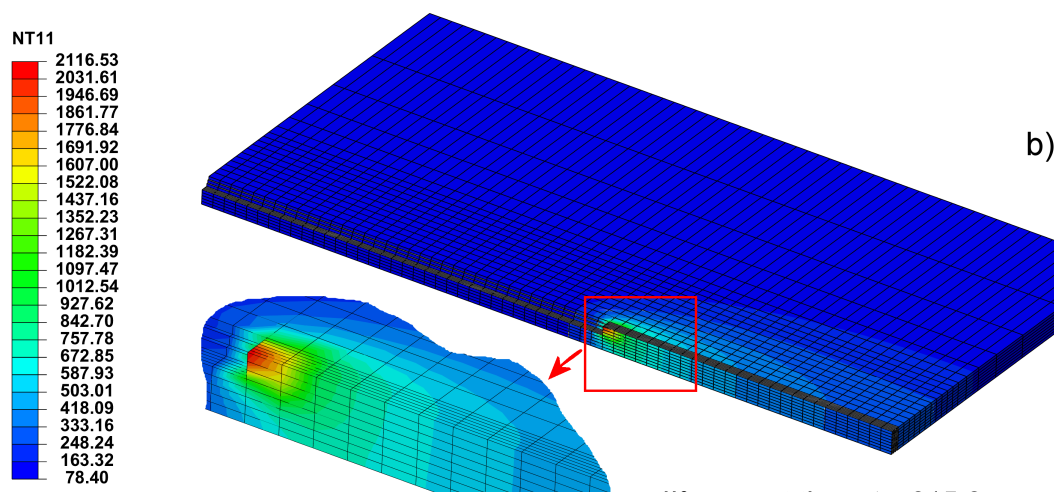

b)
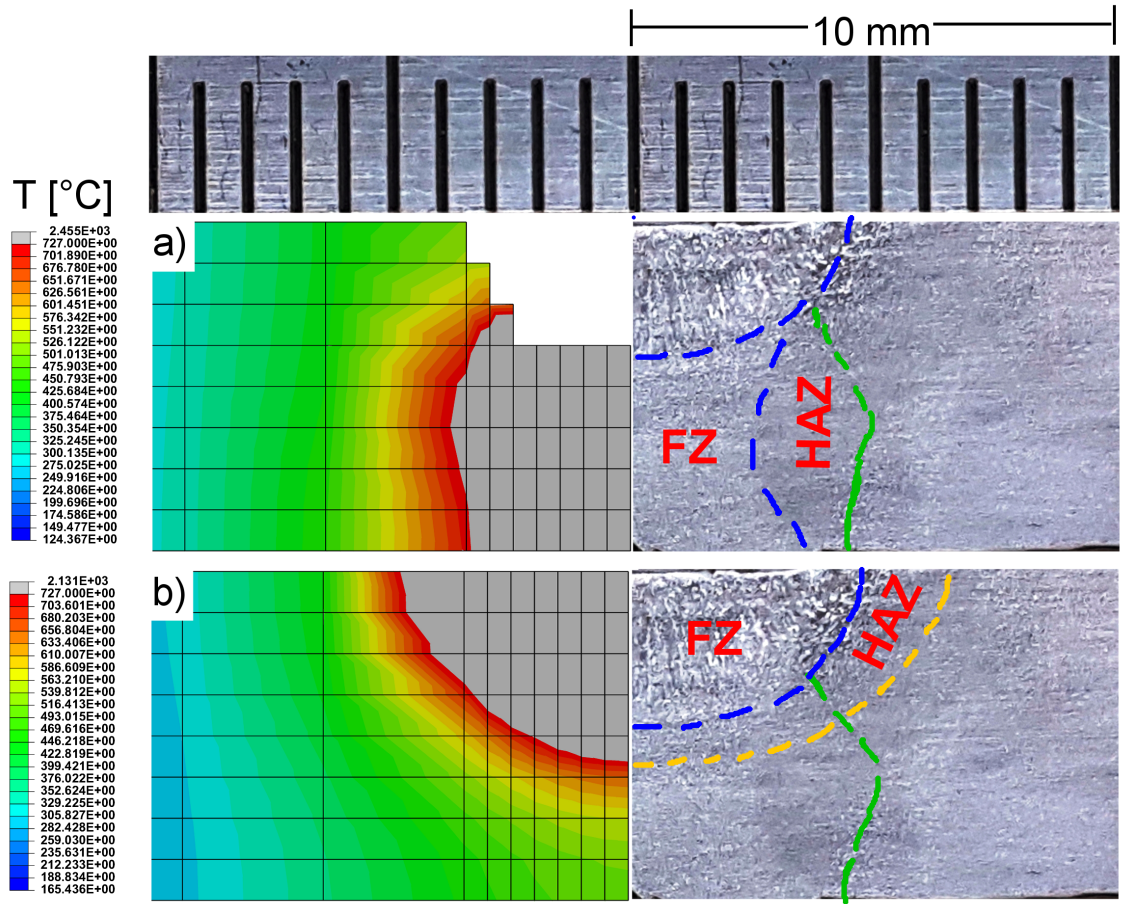

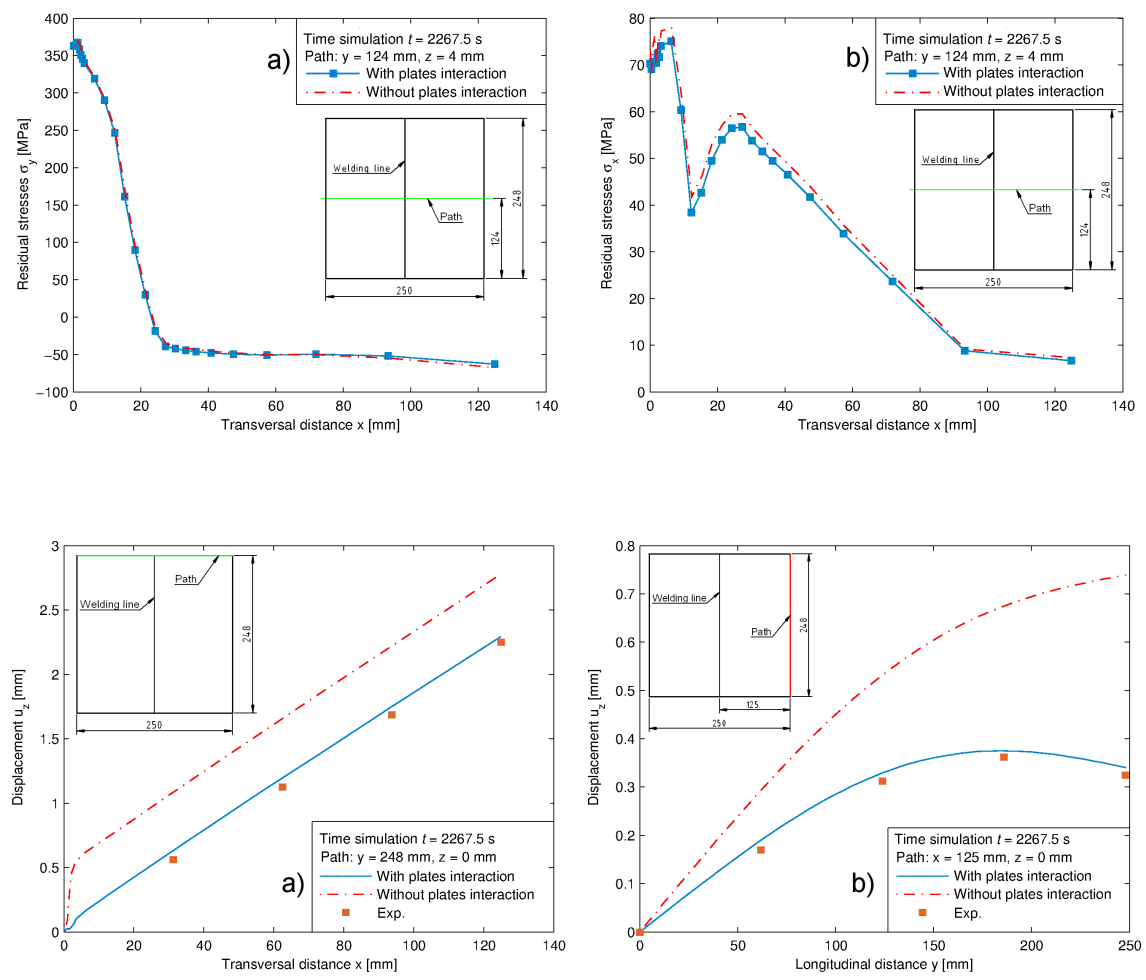